\title{
DERECHOS DE LA PERSONALIDAD Y DATOS PERSONALES
}

\author{
LUCRECIO REBOLLO DELGADO \\ Doctor en Derecho \\ Profesor Asociado del Departamento de Derecho Constitucional \\ de la UNED
}




\section{SUMARIO}

INTRODUCCIÓN. I. LA CONFIGURACIÓN CONSTITUCIONAL DE LOS DERECHOS AL HONOR, A LA INTIMIDAD Y A LA PROPIA IMAGEN COMO DERECHOS DE LA PERSONALIDAD. 1. Orígenes y realidad del honor. 2. El derecho al honor. 2.1. Caracteres del derecho al honor. 2.2. Constitucionalización del derecho. 3. La idea de intimidad. 4. Positivación jurídica de la intimidad. 5. La idea de uno mismo. 6. El derecho a la propia imagen o identidad personal. II. DELIMITACIONES JURÍDICAS ENTRE INTIMIDAD, PRIVACIDAD Y VIDA PRIVADA. III. LOS DERECHOS DE LA PERSONALIDAD COMO LÍMITE DE LA INFORMÁTICA. 1. Aspectos previos. 2. EI planteamiento constitucional y legislativo. 3. El tratamiento automatizado de datos de carácter personal. 3.1. Convenio de 28 de enero de 1981 del Consejo de Europa. 3.2. Acuerdo de Schengen de 14 de junio de 1985. 3.3. La Ley Orgánica 5/1992 de tratamiento automatizado de datos de carácter personal. 3.3.1. Objeto de la Ley. 3.3.2. Rango de la Ley. 3.3.3. Ámbito de la Ley. 3.3.4. Principios que establece la LORTAD. 3.4. Real Decreto 428/1993, de 26 de marzo. 3.5. Directiva 95/46/CE del Parlamento Europeo y del Consejo de 24 de octubre de 1995. 3.6. Directiva 97/66/CE del Parlamento Europeo y del Consejo de 15 de diciembre de 1997. 


\section{DERECHOS DE LA PERSONALIDAD Y DATOS PERSONALES}

POR

\section{LUCRECIO REBOLLO DELGADO}

Doctor en Derecho

Profesor Asociado del Departamento de Derecho Constitucional de la UNED

\section{INTRODUCCIÓN}

Todo acercamiento científico al respecto de la protección de datos de carácter personal ha de partir necesariamente de una concepción nítida de sus fines, de sus objetivos. Es frecuente que el investigador o estudioso, llevado de su deseo de solventar problemas y de apuntar soluciones, olvide el fin al que obedece su trabajo, el objetivo último de su labor. Teniendo siempre en cuenta lo afirmado, hemos de partir de tres conceptos clave en esta investigación, los cuales son: datos, carácter personal y protección técnica. El primero abre la puerta de unos elementos, de ciertos mecanismos (medios telemáticos), los cuales no son autónomos, entran en directa relación con el segundo concepto, la persona, y de esta relación se deriva la necesidad del elemento, la protección técnica. De la relación entre éstos, surgen desde la perspectiva jurídica, un auténtico mundo aún inexplorado, desconocido en gran medida $y$ al que el presente trabajo pretende realizar una modesta aportación. Para ello hace confluir una vertiente personal, humana, que a través de una regulación juridica aporta una visión conjunta del conflicto tan de actualidad, entre derechos de la persona y de- 
sarrollo tecnológico, en un ámbito concreto como es la protección de datos de carácter personal.

Hemos de ser conscientes en todo momento de que el visionado de los problemas sociales que comportan los nuevos $y$ venideros sistemas de interacción en relación a la persona, no pueden ser analizados desde una perspectiva unívoca. Coinciden todos aquellos que, de una $u$ otra manera, se acercan al estudio de este área de conocimiento, que las soluciones han de ser multidisciplinares. El estudio o conocimiento exclusivo en un ámbito o desde una disciplina determinada, está abocado al fracaso, o en todo caso al desconocimiento, si no participa de las conclusiones últimas de las diversas ciencias. Por ello el presente trabajo pretende partir desde el objeto primero de todo aquello a lo que hacemos referencia, es decir, a la persona.

Así, y partiendo de la idea de que «la finalidad genérica, que puede englobar a todas las categorías de derechos fundamentales, es favorecer el desarrollo integral de la persona humana, potenciar todas las posibilidades derivadas de su condición" ${ }^{1}$, los derechos de la personalidad se constituyen dentro de la legislación internacional y nacional como uno de los núcleos del reconocimiento y garantía de los derechos. El artículo 10 de la CE se manifiesta en favor de un reconocimiento iusnaturalista de la dignidad, es decir, entendida como eliminación de la humillación humana. Hemos de tener en cuenta que la dignidad humana constituye no sólo la garantía negativa de que la persona no va a ser objeto de ofensas o humillaciones, sino que entraria también la afirmación positiva de pleno desarrollo de la personalidad de cada individuo. Como afirma Pérez Luño², "el pleno desarrollo de la personalidad supone, a su vez, de un lado, el reconocimiento de la total autodisponibilidad, sin interferencias o impedimentos externos, de las posibilidades de actuación propias de cada hombre, de otro, la autodeterminación que surge de la libre proyección histórica de la razón humana antes que de una predeterminación dada por la naturalezan. Pese a todo, no puede entenderse como un ámbito exento de limitaciones. Los derechos de la personalidad están encuadrados por dos tipos de límites. Uno externo y otro interno. El primero alcanza hasta donde lo hace el derecho ajeno, la moral vigente, el orden público y el bien común. Desde la perspectiva interna, y como con posterioridad

1 Peces Barba, G.: Derechos Fundamentales, Facultad de Derecho de la Universidad Complutense de Madrid, Madrid, 1983, p. 109.

2 Pérez-Luño, A. E.: Derechos Humanos, Estado de Derecho y Constitución, Tecnos, Madrid, 1986, p. 327. 
veremos de forma concreta, en cada uno de los derechos de la personalidad, son inalienables, imprescriptibles, inembargables, irrenunciables e intransmisibles.

De esta forma, y siguiendo con Pérez Luño3, "la dignidad humana supone el valor básico, fundamentador de los derechos humanos que tienden a explicitar y satisfacer las necesidades de la persona en la esfera moral».

Nos queda, por último, analizar en esta introducción otro aspecto relativo a los derechos fundamentales, muy significativo en cuanto a los derechos de la personalidad. El planteamiento constitucional de cualquier derecho fundamental, se hace de forma genérica desde la perspectiva de su posible vulneración por el poder público, por los órganos del Estado. Pero en los derechos de la personalidad, se introduce una nueva posibilidad, consistente en la violación o lesión de estos derechos por otra persona, por un ciudadano, y no únicamente por partes o miembros que integran o son de la organización estatal. La configuración teórica de esta realidad se ha plasmado en Alemania a través de la denominada Drittwirkung ${ }^{4}$. No conviene olvidar, que en su origen, que se remonta a los años cincuenta, su virtualidad no fue reconocida en todos los ordenamiento jurídicos, ni aceptada por gran parte de la doctrina ni de la jurisprudencia, dado que se manifiesta sumamente conflictiva, y chocaba frontalmente con la construcción jurídica de los derechos fundamentales en esa época. Pese a ello, es hoy plenamente pacifico $y$ esta reconocido por el legislador y el Tribunal Constitucional, que la virtualidad, o eficacia de los mecanismos de garantía de los derechos fundamentales, y de forma concreta, en lo referido a la violación de los derechos al honor, a la intimidad y a la propia imagen, son también aplicables a las vulneraciones realizadas por particulares. Prueba manifiesta y contundente de ello, lo es el contenido del art. 9 de la CE y de la Ley Orgánica 1/1982, de 5 de mayo ${ }^{5}$. Ratificación de lo anterior es la Sentencia del Tribunal Constitucional $231 / 1988^{6}$, en cuyo fundamento jurídico primero se manifiesta de forma rotunda al respecto de que los de-

3 Ibidem, p. 318.

4 Drittwirkung der Grundrechte: efecto frente a terceros de los derechos fundamentales.

5 Ley Orgánica $1 / 1982$, de 5 de mayo, de protección civil del derecho al honor, a la intimidad personal y familiar y a la propia imagen.

6 El TE ha pretendido hasta 1988 soslayar un pronunciamiento sobre la virtualidad en el ordenamiento juridico español al respecto de la Drittwirkung, y asi se pone de manifiesto en sus sentencias $38 / 81,83 / 82,78 / 82,56 / 82,55 / 83,112 / 83$ y 18/84. 
rechos a la imagen y a la intimidad personal y familiar gozan de eficacia inter privatos y de acceso al amparo constitucional.

En la historia de los derechos fundamentales ha sido característica una tensión entre el individuo y el Estado, motivada por el creciente proceso de internacionalización. Lo introduce en el desarrollo de los derechos fundamentales no sólo un proceso de tensiones entre los individuos y el Estado, sino que en ella juegan también, un papel relevante, además de los poderes intranacionales los problemas de colisiones y conflictos entre individuos 7 , por lo que no cabe hablar sólo de relaciones entre individuos y estados, sino también de relaciones entre individuos y órganos intranacionales, de entre estos órganos y los estados, y de los estados entre sí, además de las relaciones interindividuales. Los derechos fundamentales no siempre cabe entenderlos como limitadores del poder estatal, sino también como limitadores de poderes privados, lo que viene a plantear el papel del Estado en relación con los derechos fundamentales. En unos casos, esta relación será negativa o de no interferencia, pero en otros es positiva, lo que implica promoción y actuaciones para su garantía efectiva.

Como indica Bobbio, los derechos de libertad nacen contra el abuso del poder del Estado y para limitar su poder, mientras que los derechos sociales, requieren, para su protección efectiva, un aumento de los poderes de aquél. Para Pérez Luño, "los derechos fundamentales han dejado de ser meros límites al ejercicio del poder político, para devenir en un conjunto de acciones positivas de los poderes públi$\cos { }^{8}$, aunque este actuar positivo no suele ser ilimitado y ha de respetar los límites constitucionales. Su necesaria actuación para el disfrute de ciertos derechos no puede atropellar otros derechos igualmente básicos, con lo que aparece el "límite del límite»9.

Dentro de las acciones positivas del Estado para la salvaguarda de los derechos fundamentales y por lo que se refiere a los datos de carácter personal, estaria la regulación normativa que los reconoce como ámbitos protegidos frente a terceros y de libre disposición de su titular.

Pero esta regulación normativa quedaría incompleta si no se incorpora la última fase dentro de una secuencia lógica de eficacia: su protección real y efectiva.

7 De Asis Rolg, R.: Las paradojas de los Derechos fundamentales como limites al poder, Debate, Madrid, 1992, p. 105.

8 Pérez Luño, A. E.: Los Derechos Fundamentales, Tecnos, Madrid, 1986.

- De Asís Roıg, obra citada, p. 106. 


\section{LA CONFIGURACIÓN CONSTITUCLONAL DE LOS DERECHOS AL HONOR, LA INTIMIDAD Y LA PROPIA LMAGEN}

\section{Orígenes y realidad del honor}

El concepto de honor procede del griego ainos, cuyo significado es el de alabanza, halago, y que posee una fuerte implicación social. $\mathrm{Ha}$ de distinguirse en la actualidad entre honor y honra. Ésta última es algo subjetivo, relativo a las virtudes que el hombre posee; por contra, el honor es la buena fama o reputación que una persona merece al conjunto social. También hemos de diferenciar, con De Castro ${ }^{10}$, el honor de la fama. "El honor está referido directamente al trato dado o recibido por los demás, y la fama es el rumor, voz públican, renombre, que está relacionado con el eco que la persona produce en la opinión pública». De esta forma el honor se aproxima a lo que la persona piensa o considera de sí misma. Por contra, la fama es la opinión externa a la persona, lo que los demás piensan de ella. Algunos autores van un poco más allá, distinguiendo entre honor subjetivo y objetivo. Es el caso de Novoa Monreal"1, cuando manifiesta que "todo ser humano tiene derecho a ser tratado de manera compatible con su dignidad, la cual tiene una manifestación directa y clara en la estimación que él siente por sí mismo (honor subjetivo) y que espera de los demás (honor objetivo)». Independientemente de aquella visión por la que optemos del honor (objetiva o subjetiva), el honor no es algo que se tiene (concepción objetiva) o que se siente (concepción subjetiva), sino una parte integrante del concepto globalizante de la dignidad humana.

\section{El derecho al honor}

Al igual que otros derechos, el honor tiene su raíz en la idea de patrimonialidad o pertenencia a la persona. Se configura y desarrolla en forma primigenia en planteamientos históricos liberales.

Durante el siglo XIX no existe una concepción genérica del derecho al honor, sino más bien una adscripción de aquél referido a una de-

10 De Castro, F.: Temas de Derecho Civil, Madrid, 1970, p. IX.

11 Novoa Monreal, E.: Derecho a la vida privada y libertad de información. S. XXI, Madrid, 1989, p. 74. 
terminada clase social. El honor era parejo con el prestigio personal y social. De esta forma, la aristocracia por ejemplo, incluía dentro de sus propiedades la del honor, de la misma forma que las mujeres públicas estaban desposeídas de él. Además de ello, el honor tiene una implicación eminentemente privada. Sus disputas se resuelven en base al denominado "Código de Honor".

Al igual que en otros muchos derechos, el honor ha sufrido un proceso de democratización, de generalización social, de tal forma, que hoy toda persona tiene derecho al honor por el mero hecho de serlo. De esta forma, el derecho al honor se configura como «la pretensión de respeto que corresponde a cada persona como consecuencia del reconocimiento de su dignidad $"{ }^{12}$.

La protección del derecho al honor tiene tres ámbitos muy definidos y en cada uno de ellos se establecen procedimientos distintos de protección. Asi, cabe la protección penal, civil y constitucional del honor. Analizamos brevemente las dos primeras y en forma algo más extensa la última.

El honor se protege en el ámbito penal mediante la tipificación de la injuria ${ }^{13}$ (expresión proferida o acción ejecutiva en descrédito o menosprecio de otra persona) y de la calumnia ${ }^{14}$ (falsa imputación de un delito de los que dan lugar a procedimiento de oficio).

La protección civil al honor se concreta en el art. 1.902 del Código Civil ${ }^{15}$ y por los procedimientos judiciales ordinarios, $y$ de forma concreta por los establecidos en la Ley Orgánica 1/1982.

En el ámbito constitucional se protege el honor en base a tres mecanismos o procedimientos. Una de las vías es la específica de los derechos de la personalidad, y las otras dos comunes a los derechos fundamentales.

a) Derecho de rectificación. Pese a que este derecho no tiene rango constitucional, ya que es regulado en la Ley Orgánica $2 / 1984$, de 26 de marzo, por la cual se establece un procedi-

$12 \quad$ S.T.C. de 20 de julio de 1988.

13 Art. 208 del Código Penal.

14 Art. 205 del Código Penal.

15 Cuyo contenido es el siguiente: «El que por acción u omisión causa daño a otro, interviniendo culpa o negligencia, está obligado a reparar el daño causado". 
miento rápido e independiente de todas las acciones civiles y penales que se puedan ejercer. Procede este derecho "frente a hechos inexactos de nociva divulgación" ${ }^{16}$.

b) Otra forma de protección constitucional del derecho al honor, lo constituye el preferente y sumario ante la jurisdicción ordinaria. Regulado en la Ley $62 / 78$ de protección jurisdiccional de los derechos fundamentales de la persona.

c) Por último, hemos de establecer también como elemento de garantía frente a las violaciones del derecho al honor, el recurso de amparo. Este tiene su reconocimiento en la propia Constitución (art. 161.1.b) y en la Ley Orgánica del Tribunal Constitucional. En este aspecto, participan algunos autores de la idea, en absoluto pacífica, de posibilitar únicamente el recurso, en el supuesto de que la violación provenga de un órgano estatal. Pero como hemos manifestado, es una realidad, que el recurso de amparo por violación no sólo del derecho al honor, sino también a la intimidad y a la propia imagen, tienen virtualidad tanto frente a las posibles violaciones o intromisiones del poder público, como de los particulares.

\subsection{Caracteres del derecho al honor}

Son caracteres propios del derecho al honor, aquellos que los son de los derechos de la personalidad:

- El derecho al honor es innato e igual. Como ha quedado sentado, corresponde a toda persona por el significativo hecho de serlo, de tener atribuida su dignidad. De ello se deriva la igualdad, independientemente de los usos sociales o de la propia actuación de la persona.

- El derecho al honor es irrenunciable, inalienable e indisponible. La persona no puede renunciar a parte de su personalidad o negar parcialmente ésta. Si es persona, está dotada de dignidad, y por consiguiente de honor. También es inaliena-

16 TENORIO SÁnCHEZ, P. J.: "Derecho al honor y libertad de expresión», en la obra de VV.AA., Estudios sobre derecho de la Información, UNED, Madrid, 1994, pp. 144 y ss. 
ble el derecho que estudiamos, dado que no cabe enajenación del mismo. No puede tampoco la persona disponer de parte de su honor o comerciar con éste. Cabe esta posibilidad en los derechos de la intimidad y a la propia imagen, pero no en el derecho al honor. "La persona puede desprenderse de algunas de las facultades que la integran (hacer una película, ser fotografiado, etc.), sin que ello implique, en modo alguno, abdicación o renuncia de su titularidad personalísiman ${ }^{17}$. El honor no puede ser objeto de desprendimientos parciales, o se tiene o no se tiene. En todo caso, al ser un derecho personalísimo, no puede cederse a otra persona o ser adquirido por tercero.

- El derecho al honor no tiene carácter patrimonial. Pese a lo que pudiera esta afirmación encarnar de contradictorio, hay que ratificar que el derecho al honor no es susceptible de patrimonialización ni de apropiación. Sí son susceptibles de ello, el derecho a la propia imagen, o incluso el derecho a la intimidad. Como afirma López Díaz ${ }^{18}$, «nadie podrá negociar con eficacia, la renuncia perpetua a proteger su honor, sin embargo, la renuncia fraccionada y periódica está amparada por ley".

- Por último, el derecho al honor es imprescriptible. No se extingue por inactividad o falta de uso de su titular. Incluso alcanza más allá de la propia vida del sujeto, dado que cabe la posibilidad de defensa del honor del fallecido.

\subsection{La constitucionalización del derecho}

Hemos de partir de la nítida ausencia de un reconocimiento concreto del derecho al honor en nuestro constitucionalismo histórico. Si bien existe el reconocimiento de manifestaciones del derecho a la intimidad (inviolabilidad de la persona, domicilio, correspondencia, etc.), hasta la vigente Constitución, no puede hablarse de un reconocimiento concreto y específico del derecho al honor.

17 LóPEz Díaz, E.: El derecho al honor y el derecho a la intimidad, Dykinson, Madrid, 1996, p. 59.

$18 \quad$ Ibidem, p. 63. 
El constituyente de 1978 busca como modelo la Constitución portuguesa de 1976, y de forma concreta su art. 33, donde se reconoce "el derecho a la identidad personal, al buen nombre, reputación y a la reserva de su intimidad en la vida privada y familiar". De esta forma, el art. 18 de la vigente C.E. acoge en su apartado primero por vez primera el honor como derecho, y además como derecho fundamental. En el mismo apartado se referencian en igualdad de garantía a la intimidad y a la propia imagen.

No parece seguir el constituyente español de 1978 las prescripciones que el derecho en el ámbito internacional ya había realizado al respecto del honor. La Declaración Universal de Derechos del Hombre y del Ciudadano aprobada por la 183 Asamblea General de las Naciones Unidas, de fecha 10 de diciembre de 1948, reconoce el derecho al honor individual, estableciendo en su art. 12 que $" . .$. nadie puede ser objeto de injerencias arbitrarias en su vida privada, su familia, su domicilio, o su correspondencia, ni de ataques a su honor y a su reputación. Toda persona tiene derecho a la protección de la ley contra tales injerencias 0 ataques".

En el mismo sentido, no cabe entender el contenido del art. $18 \mathrm{CE}$ sin hacer referencia previa al art. 10.1 del mismo texto. Si el fundamento del orden político y la paz social es el respeto a la dignidad de la persona, los derechos inviolables que le son inherentes y el libre desarrollo de la personalidad, el derecho al honor es una consecuencia necesaria de ello ${ }^{19}$.

El art. 18 en su totalidad tuvo un trámite sencillo en el iter legislativo, sin enmiendas, a excepción de la formulada en el Senado por Camilo José Cela, el cual entiende como innecesaria la referencia que el art. 18.1 realiza a la intimidad personal y familiar, ya que intimidad significa "zona espiritual íntima de una persona o de un grupo, especialmente de una familia». Por ello, proponía el citado senador dejar el contenido del artículo en su apartado primero de la forma siguiente: "Se garantiza el derecho al honor, a la intimidad y a la propia imagen". Pero como con anterioridad hemos manifestado, el art. 33 de la Constitución portuguesa de 1976 influye de forma muy considerable en el constituyente español.

19 Así lo aprecia el Tribunal Constitucional en la sentencia 214/1992, de 11 de noviembre, en el fundamento jurídico $10^{\circ}$, donde manifiesta que «el derecho al honor y otros de los derechos reconocidos en el art. 18 de la C.E. aparecen como derechos fundamentales vinculados a la propia personalidad del individuo, derivados sin duda de la dignidad de la persona que reconoce el art. 10 C.E.". 
El art. 18.1 de la C.E. ha sido desarrollado, como ya se citó, mediante Ley Orgánica, la cual resume la protección en dos ámbitos concretos; la obligación de respeto, por parte de terceros, de la intimidad y el honor de los demás, obligación que es genérica e indeterminada; y en el deber de abstención que tiene que cumplir cada individuo frente a los demás.

Pese al campo jurídico que abre la Ley Orgánica referida, no entraremos en su estudio, en base a que la perspectiva del presente trabajo son los derechos al honor, la intimidad y la propia imagen desde la óptica de su interacción con la protección de datos personales, contenido propio de otra Ley Orgánica ${ }^{20}$, en este caso en desarrollo del art. 18.4 de la C.E. Además de ello, y como la propia Ley Orgánica de 1982 establece, algunos de estos derechos gozan además de una protección penal, la cual disfruta de una aplicación preferente, por ser, sin duda, de más fuerte efectividad. Por ello entendemos adecuado en el presente estudio, entrar en el conocimiento de la ley de protección de datos personales, más que en la Ley Orgánica de 1982, dado que ésta es genérica, mientras que aquélla previene y garantiza una violación concreta.

\section{La idea de intimidad}

Como han puesto de manifiesto diversos autores ${ }^{21}$, la intimidad puede ser contemplada desde diversos aspectos, $y$ en esencia desde tres: como fenómeno, como idea y como derecho. En su primer ámbito, todos los estudiosos coinciden en la necesidad universal de intimidad. Incluso autores como Westein ${ }^{22}$, desde experiencias zoológicas, referencian la intimidad ligada al instinto de territorialidad. La intimidad como derecho es la manifestación y reconocimiento jurídico de una necesidad social. El derecho reconoce un ámbito reservado e inaccesible de toda persona, a terceros. Este aspecto, que es el más significativo desde nuestra perspectiva, lo analizaremos con posterioridad más en detalle. Nos queda por último una manifestación de la intimidad, como es la idea de intimidad. A este respecto, no todas las socie-

20 Ley Orgánica 5/1992, de 29 de octubre, de regulación del tratamiento automatizado de datos de carácter personal.

21 De forma significativa y brillante lo hace Ruiz Miguel en su obra La configuración constitucional del derecho a la intimidad,. Tecnos, Madrid, 1995, pp. 25 y ss.

22 Westein, Alan F.: Privacy and freedom, Nueva York, 1970, 6. ${ }^{a}$ ed., p. 13. 
dades tienen conciencia de intimidad, lo cual no implica su ausencia de uso. Como afirma Ruiz Miguel ${ }^{23}$, "la forma de conciencia sobre la intimidad, no se encuentra en todas las sociedades, y aún en las sociedades en que se encuentra, el grado de teorización puede variar».

En lo referido al origen de la intimidad, no parece existir acuerdo, dándose muy variadas raíces. Los denominados racionalistas entienden que la idea de intimidad aparece con la disgregación feudal, afirmando que el nacimiento de la intimidad coincide con la ratificación revolucionaria de los derechos del hombre, y en concreto está ligada al nacimiento de una clase social, la burguesía. De esta forma la teoría racionalista hace coincidir la idea de intimidad con el nacimiento del derecho. Frente a esta opinión existe la teoría, denominada histórica, que liga su origen al término propiedad (propius), como lo propio de uno. Así, ya en la antigüedad clásica existen atisbos de una idea de intimidad. Aristóteles por su parte es consciente de la distinción entre lo público y lo privado, utilizando incluso el concepto de vida privada. En Roma tampoco es desconocida la idea de intimidad, de tal forma que vemos en Séneca una distinción entre el hombre exterior (ad alia) e interior (ad animum, ad se). También Roma nos ha dejado el origen etimológico. Así, cuando Séneca quiere aludir a la interioridad habla de intus, adjetivo que deriva del superlativo intimus. Con el cristianismo se afianza la idea o el concepto de intimidad, su reconocimiento será mayor. De esta forma, San Agustín en su obra Confesiones realiza un análisis completo de la idea que referimos, y que será la base para el estudio posterior por parte de Kant y de Descartes. Con la llegada del liberalismo, serán muchos los autores que acogen la idea de intimidad como un ámbito de libertad del individuo (Hobbes, Locke, Constant, entre otros). Por su parte, tanto Kant como Rousseau entienden que la capacidad para dirigirse a sí mismo pertenece a todos los hombres, afirmando que ninguna ley puede privar de parte de la libertad racional humana.

\section{Positivación jurídica de la intimidad}

En un principio, el derecho protege ciertas manifestaciones de la intimidad. No existe en Grecia un reconocimiento jurídico de la intimidad, debido al concepto globalizante y socializador de la Polis. Roma, 
por contra, realizará la distinción entre derecho público y privado. Dentro de éste último, se reconocen manifestaciones del derecho a la intimidad como la protección de la correspondencia y del domicilio.

Si entendemos, como gran parte de la doctrina, que la libertad religiosa es una manifestación de la intimidad, el Edicto de Milán del año 313 es un hito, dado que los emperadores Constantino y Lucinio acuerdan "dar asi a los cristianos, como a todos, la libertad de seguir la religión que cada cual quiera". El emperador Constantino dio más muestras de respeto y de reconocimiento de la intimidad. Suprimió por completo la acusación pública de adulterio, al entender "que es cosa indigna que matrimonios tranquilos se vean perturbados por la audacia de los extraños» ${ }^{24}$.

En la Edad Media estará presente la concepción cristiana del derecho a la intimidad, fundamentalmente a través de la obra de San Agustín y del redescubrimiento del Derecho Romano. Junto a ello, la aportación de lo propio, de la libertad del individuo frente a lo público, influirá de forma definitiva en reconocimientos puntuales de manifestaciones del derecho a la intimidad. Ello arrancará de la idea de dignidad del hombre. Esto se traducirá en la manifestación concreta en la inviolabilidad del domicilio (tranquilitas domestica), que en Castilla será entendida como la paz de la casa. También las Cortes de León de 1188 recogen el derecho a la inviolabilidad del domicilio ${ }^{25}$. Este derecho, como manifestación del derecho a la intimidad, también será recogido en otros textos ${ }^{26}$.

En la Edad Moderna aparece la protección de la libertad de conciencia, o la libertad religiosa, y se reconoce el derecho a gran número de manifestaciones de intimidad. Hemos de tener en cuenta que en esta época surgirán las primeras constituciones modernas (Estados Unidos 1787) y las primeras declaraciones de derechos (francesa de 1789). En España, previo al constitucionalismo se reconoce la inviolabilidad del domicilio, el secreto de las comunicaciones, así como la intimidad corporal.

Pese a todo lo manifestado, no puede hablarse de una configuración propia del derecho a la intimidad hasta $1890^{27}$. Con anterioridad,

24 Cita recogida de la obra de RuIz Miguel, La configuración constitucional del derecho a la intimidad, p. 51.

25 Decreto 11.

26 Fuero Viejo de Castilla de 1250. Leyes de Estilo de 1300 entre otras.

27 Asunto Warren \& Brandeis. 
existe el reconocimiento de aspectos de la intimidad, pero no hay una concepción global del derecho, ni una conciencia de su necesidad, asi como tampoco una delimitación propiamente jurídica. La construcción jurídica que surge del caso Warren \& Brandeis, pretende poner límite a las intrusiones de la prensa en la vida y honorabilidad de las personas. Como afirma Ruiz Miguel ${ }^{28}$, «este aspecto ya se encontraba jurídicamente protegido en el continente europeo merced a las antiguas normas que protegían contra la difamación y el libelo, para preservar el honor y buena fama de las personas". Pese a todo, la construcción que surge en 1890 en Estados Unidos configura un nuevo derecho que pasará en primer lugar a formar parte del ordenamiento norteamericano a través de la jurisprudencia. Con posterioridad dará el salto a las declaraciones internaciones de derechos ${ }^{29}$, para poco después pasar a los textos constituciones (fundamentalmente a los europeos). De esta forma, no hay en el constitucionalismo histórico español ningún precedente del reconocimiento del derecho a la intimidad en su integridad o como manifestación del mismo. Existía, como hemos visto, el acogimiento constitucional de ciertos aspecto de la intimidad (prohibición de entrada en el domicilio, de violación de la correspondencia, etc.), pero no un reconocimiento expreso y determinado del derecho a la iritimidad.

La Constitución de 1978, en su artículo 18 agrupa en un mismo precepto, el reconocimiento de tres nuevos derechos, como consecuencia de su vigencia internacional, y de la necesidad constatada de tener acogida jurídico-constitucional.

28 Obra citada, p. 57.

29 La Declaración Universal de Derechos Humanos de 1948, en su art. 12 establece que «nadie será objeto de injerencias arbitrarias en su vida privada, su familia, su domicilio o correspondencia...". El Pacto Internacional de Derechos Civiles y Políticos de Nueva York de 19 de diciembre de 1966, en su art. 17.1 establece el mismo contenido que el citado, aludiendo también a la vida privada en el art. 14.1. En igual sentido se pronuncia el Convenio Internacional sobre Derechos del Niño de la Asamblea de Naciones Unidas de 20 de noviembre de 1989 (arts. 16 y 40.2.b). De la misma forma, es de significativa relevancia el Convenio Europeo para la Protección de los Derechos Humanos y Libertades Públicas, firmado en Roma el 4 de noviembre de 1950, en cuyo art. 8 se consagra el derecho a la intimidad de la forma siguiente: Art. 8.1 "toda persona tiene derecho al respeto de su vida privada y familiar, de su domicilio y de su correspondencia». El art. 8.2 establece que "no podrá haber injerencia de la autoridad pública en el ejercicio de este derecho, sino en tanto en cuanto esta injerencia esté prevista por la ley y constituya una medida, que en una sociedad democrática, sea necesaria para la seguridad nacional...". 


\section{La idea de uno mismo}

Algún método de representación de imágenes o ideas ha sido común y consustancial al propio hombre en toda época. Grecia dará figura humana a sus dioses, a la vez que los expone a la vista de todos en la Polis. El hombre y su imagen cobran valor cotidiano, reconocible. Surgida la pintura y la escultura, y tras el desarrollo en el mundo occidental de las denominadas artes de la figuración, en 1839, la fotografía desplaza la pintura y la escultura en el monopolio de la representación reconocible, derivando aquéllas a elementos figurativos y abstractos. Con posterioridad, aparece el proceso de reproducción de la imagen en movimiento. Surgirá el cinematógrafo y la televisión. Con esta breve evolución, hemos llegado al que podríamos denominar mundo de la imagen.

De esta forma, la figura humana y su representación, es decir, su imagen, constituye el signo más inequívoco de identificación de una persona. El concepto imagen proviene del latín imago, imaginis, entendiéndose hoy por imagen, la figura, representación, semejanza y apariencia de una persona o cosa.

La importancia de la propia imagen tiene dos proyecciones significativas. Una primera alcanza de forma introspectiva al propio individuo y al concepto de sí mismo, con dos ámbitos sustanciales, uno físico, corporal, y otro mental o psíquico. En lo que hace referencia a la segunda proyección, es externa, hacia fuera, con respecto a los demás, y procura o pretende reservar o realizar una imagen acorde con lo que nosotros pensamos o entendemos de nosotros mismos.

Podemos afirmar, con Ruiz Tomás ${ }^{30}$, que «es imagen toda expresión que haga sensible un objeto carente, en sí mismo, de susceptibilidad para manifestarse, o bien el medio por el que una cosa se destaca en el ambiente externo con más fuerza de la que antes tenía dispuesta para representarse externamente. Es, pues, la imagen algo representativo".

Los dos aspectos a los que con anterioridad hemos aludido, se ven hoy potenciados de forma muy significativa, al igual que lo está todo lo relacionado con la persona. El mundo de la información y de la comunicación potencia los posibles mecanismos de lesión o quebran-

30 Rulz TomÁs: "Ensayo sobre el derecho a la propia imagen», Revista General de Legislación y Jurisprudencia de 1931, p. 46. 
tamiento de nuestra imagen tanto en el ámbito externo como en el interno. De ello la necesidad de configurar un nuevo derecho, como hace nuestra Constitución y de dotarlo de autonomía y también de garantías.

\section{El derecho a la propia imagen o identidad personal}

No faltan autores, que sustentan la opinión de que el derecho a la propia imagen carece de sentido peculiar, puesto que no es más que una categoría subsidiaria del derecho al honor. De esta forma Ferrara entiende que "la actual tendencia dominante es la que presenta la tutela de la imagen como una forma exquisita de la sensibilidad del honor de la persona " ${ }^{31}$. También es verdad que, como afirma Herrero-Tejedor ${ }^{32}$, el derecho a la propia imagen aparece unido al derecho al honor o la intimidad, como una mera manifestación de los mismos, por lo cual, "tarda más en adquirir un reconocimiento independiente». Quizás por ello parte de la doctrina sigue manteniendo la filialidad del derecho a la propia imagen en el derecho al honor, o con la intimidad.

Pese a todo lo manifestado, entendemos que si bien el derecho a la propia imagen puede presentar concomitancias, y de tener una raíz común, tanto con el derecho al honor y con el derecho a la intimidad, no cabe duda de que se trata de un derecho autónomo y virtual en nuestro ordenamiento jurídico. La autenticación de esta afirmación radica en la posibilidad de lesionar o realizar una intromisión en el derecho a la propia imagen sin que exista violación del honor o intromisión en la intimidad. De esta forma se manifiesta también el contenido de la Ley Orgánica 1/82, que si bien en un principio relaciona la propia imagen con el derecho a la intimidad, y en concreto, en alguno de los supuestos del art. 7.5, también establece la posibilidad de intromisión ilegítima en su ámbito exclusivo en el art. 7.6.

Partiendo ya de la base de la configuración del derecho a la propia imagen como un derecho autónomo, fundamental y constitucionalmente reconocido, nos cabe ahondar en su definición. Son pocos los juristas que han esbozado una definición de tal derecho. Entre los 1990 , p. 92.

31 Ferrara, F.: Trattato di diritto civile italiano, Roma, 1950, vol. Y, p. 480.

32 Herrero-Tejedor, F.: Honor, intimidad y propia imagen, Colex, Madrid, 
que lo hacen, destaca de forma significativa Gitrama ${ }^{33}$, quien entiende que el derecho a la propia imagen ues un derecho innato de la persona, que se concreta en la reproducción o representación de la figura de ésta, en forma visible y reconocible. Es un derecho subjetivo de carácter privado y absoluto. Es un derecho personalísimo, pero dotado de un contenido potencialmente patrimonial. Es un derecho inalienable e irrenunciable $y$ en general inexpropiable... en fin, es un derecho imprescriptible».

El primer reconocimiento normativo del derecho a la propia imagen tuvo lugar en Alemania en $1907^{34}$, a pesar de que ya se formulase su concepción también en el caso Warren \& Brandeis.

Nuestro constitucionalismo no conoce hasta 1978 derecho alguno identificable con el actual derecho a la propia imagen, si bien existen manifestaciones en algunas sentencias tendentes a poner de manifiesto la necesidad de su reconocimiento. $Y$ mientras ello sucede, acuden a la argumentación en base a principios generales del derecho ${ }^{35}$.

De los tres derechos hasta aquí tratados, no cabe duda de que el más dado o susceptible de ser lesionado, mediante la utilización indebida de datos de carácter personal, y el que presente una mayor interacción con los modernos medios tecnológicos, es la intimidad. Por ello utilizamos a este derecho como línea maestra o como más significativo dentro de una visión de vida privada.

\section{DELIMITACIONES JURÍDICAS ENTRE INTIMIDAD, PRIVACIDAD Y VIDA PRIVADA}

Se hace necesario, visto lo anterior, concretar y delimitar jurídicamente el significado que poseen cada uno de los términos que utilizamos. Ello se hace imprescindible si queremos un acercamiento serio

33 Gitrama: Voz «imagen, derecho a». Nueva Enciclopedia Jurídica, tomo XI, Barcelona, 1962, p. 326.

${ }^{34}$ Debido al clamor popular suscitado frente a la actuación de dos fotógrafos, que habian reproducido la imagen del Canciller Bismarck en el lecho de muerte, contra la voluntad de sus familiares.

${ }_{35}$ Véase en tal sentido la sentencia de la Sala Civil de la Audiencia de Zaragoza de fecha 9-VI-1967. 
a los derechos de la personalidad, pero más aún si queremos establecer el alcance, contenido y ámbito de la protección de aquellos derechos, y de forma concreta del derecho a la intimidad. De lo contrario, no alcanzaremos nunca a comprender el verdadero significado del derecho que nos ocupa.

En esta tarea es conveniente un acercamiento, aunque sea somero, a las fórmulas que han utilizado otros ordenamiento jurídicos e incluso el derecho internacional; ello nos dará pautas en la función clarificadora.

La doctrina alemana ha distinguido lo siguiente: intimsphäre, concepto que hace referencia a la esfera de lo secreto y se viola cuando se llega al conocimiento de hechos o noticias que deben permanecer ocultas, o cuando éstas se difunden; privatsphäre, que equivale a nuestra noción de lo intimo y protege el ámbito de la vida familiar y personal. Finalmente recoge la doctrina alemana el concepto de individualsphäre, que se refiere a todo aquello que atañe a la peculiaridad o individualidad de la persona. Esta forma de comprensión de lo privado se denomina la teoría de las esferas, Sphärentheorie, alumbrada por Hubmann ${ }^{36}$ y que tuvo una extensa acogida en Europa y en Estados Unidos $^{37}$. El problema de esta teoría radica en la imposibilidad de configurar cada una de las esferas como compartimentos estancos, sin interrelación. Como pone de manifiesto Morales Prats ${ }^{38}$, estas esferas se comunican y pueden pasar a formar parte unas de otras de modo que constituyen una espiral, en la que por medio del consentimiento de su titular los componentes de la zona de secreto pueden pasar a formar parte de las relaciones de confianza, o bien ésta a la esfera privadan.

La teoría de las esferas ha sido en gran medida desechada o superada por la jurisprudencia del Tribunal Constitucional Federal, a partir de la sentencia de 15 de diciembre de 1983, sobre el Censo de Población, que da origen, a un nuevo derecho en el ordenamiento jurídico alemán, denominado "autodeterminación informativa». Éste se resume en la posibilidad del individuo de determinar quién, qué y con qué ocasión puede conocer, o utilizar un tercero datos que le afectan. Con

36 Hubmann, H.: Das Personlichkeitsrecht, 2." ed., Colonia, 1967.

37 También Westein, en Privacy and Freedom, Nueva York, 1967, p. 7, opta por la teoria de las esferas, a cuyos niveles denomina soledad, relaciones íntimas, anonimato y reserva. 1984, p. 129.

38 La tutela penal de la intimidad: privacy e informática, Destino, Barcelona, 
ello se avanza en el concepto de intimidad desde la perspectiva externa. De esta forma la intimidad no es sólo aislamiento y reserva, sino también el control de lo externo a nosotros y que nos pertenece, o que pertenece a nuestra vida privada.

- En la doctrina italiana destacan las conclusiones a las que llega Frosini ${ }^{39}$, el cual considera que existen cuatro fases o modalidades de aislamiento: $1{ }^{\text {a }}$, la soledad; entraña la imposibilidad física de contactos materiales; $2{ }^{2}$, la intimidad; el individuo, sin encontrarse aislado, reduce sus contactos, se encuentra en un grupo reducido en el que se dan relaciones especiales, ejemplo de ello lo son los ámbitos conyugal y familiar; $3 .^{a}$, el anonimato; éste se da cuando el individuo, aun estando expuesto a contactos con una multiplicidad de personas, mantiene la libertad para identificaciones individuales; y por último, la 4. ${ }^{a}$, la reserva, que consiste en la creación de una barrera psicológica frente a intromisiones no deseadas. Como puede comprobarse, las denominaciones de la doctrina italiana varían, pero la esencia de la fundamentación es la misma, es decir, la teoría de las esferas. Pese a ello, conviene destacar las conclusiones a las que llega De Mattia ${ }^{40}$, quien entiende la necesidad de protección jurídica y de respeto a la vida privada y familiar, dado que tiene una significación social, al garantizar al individuo una zona reservada, cerrada a las intromisiones e interferencias. Lo más significativo de su aportación lo constituyen los contenidos de la vida privada, los cuales a su entender son:

- Defensa de la integridad física y mental.

- Defensa de la integridad intelectual.

- Defensa de la integridad moral.

- Apropiación de elementos o atributos de la personalidad individual.

- Defensa de la libertad de acción del sujeto, contra las interferencias graves que pueden limitarla.

39 Frosini, V.: // diritto nella società tecnológica, Giufré, Milán, 1981, pp. 279 y ss.

40 De Mattia, A.: "Le juge et le droit au respect de la vie privée. Raporte Génerale", en Quinto Congreso Internacional de la vida privada, Firenza, octubre de 1974. Giufrré Editore, Milán, 1978, pp. 44 y ss. 
- Defensa de la vida privada contra toda forma de indiscreción, adquisición y difusión sin consentimiento previo del interesado.

- Defensa del secreto y de las comunicaciones privadas.

- Por su parte, ni la doctrina del Reino Unido, ni la jurisprudencia, han elaborado un concepto de privacidad. Incluso la jurisprudencia ha mantenido una negativa concreta a formular un concepto de rigth to privacy. Han sido varios los intentos de configuración de un concepto de intimidad (privacy) en el ordenamiento inglés. El último es el informe británico elaborado en 1971 por el Younger Committee on Privacy. En él se constata que «la opinión pública de los paises desarrollados sitúa el respeto a la vida privada en el lugar prioritario de sus aspiraciones de protección de los derechos humanos» ${ }^{41}$. Los trabajos de la comisión pasaron sin conseguir una configuración del derecho a la intimidad. Lo mismo había ocurrido diez años antes. En 1961 Lord Mancroft había presentado un proyecto de ley regulador de la intimidad, pero, como él mismo reconoce, el «proyecto fracasó porque fui incapaz de establecer una distinción precisa entre lo que el público tiene derecho a conocer y lo que un hombre tiene derecho a conservar para sí mismo" ${ }^{42}$.

- La doctrina y la jurisprudencia norteamericana han sido, quizás, quienes más han abundado en el concepto de privacidad, así como en el derecho, de tal forma que su evolución conceptual ha sido muy significativa y cuyos resultados podíamos resumir también en cuatro ámbitos o áreas: $1 .^{2}$, libertad o seguridad frente a cualquier tipo de intromisiones indebidas en la esfera privada; $2 .^{a}$, garantía de respeto a las opciones personales en materia de asociación o creencias; $3 .^{\mathrm{a}}$, tutela de la libertad de elección sin interferencias, y por último; 4. ${ }^{a}$, posibilidad de los individuos y grupos de acceder y controlar las informaciones que les atañen. Esta evolución se ha plasmado en la obra de Westein, Privacy and freedom, estudio que aporta una definición categórica de privacy, entendiendo que es «el derecho al control de la información referente a uno mismo". Con posterioridad Lusky ${ }^{43}$ amplía el concepto de privacidad, de forma que ya no tiene únicamente un sen-

41 Price of Privacy de 1971, p. 36.

42 The Times, Londres, 22 de octubre de 1969.

43 LuSkY, L.: "Invasion of Privacy: a clarification of concepts", en Columbia Law Review, n. 72 , pp. 693 y ss. 
tido estático de defensa de la vida privada del conocimiento ajeno, sino que tiene una función dinámica, la posibilidad de controlar la circulación de informaciones relevantes para cada sujeto.

Esta concepción es la que ha tenido mayor repercusión en el derecho universal. La primera acepción de privacidad se identifica con dignidad, la segunda lo hace con la idea de libertad. De esta forma, la privacidad ha pasado de ser el derecho de exclusión de los demás del ámbito privado, a ser el espacio de soberanía de un individuo considerado en su dimensión integral. Pese a ello, la dificultad de precisar el concepto privacy queda clara en el ordenamiento de Estados Unidos en 1967, cuando la Office of Science and Technology of the Executive Office of the President manifiesta "que el derecho a la vida privada es el derecho del individuo de decir por sí mismo en qué medida compartirá con otros sus pensamientos, sus sentimientos y los hechos de su vida privada. En realidad lo que es privado varía según los días y las circunstancias" ${ }^{44}$.

- En la doctrina francesa parece haber un menor interés por la configuración del derecho a la intimidad; por ello, las elaboraciones doctrinales son de menor calado. Kaiser ${ }^{45}$ realiza una diferenciación entre ataques al secreto y ataques a la libertad. Entre los primeros se incluye la divulgación de lo privado (dar publicidad) a terceros de aspectos relevantes de la vida personal y familiar. En el segundo aspecto se incluye la investigación de la vida privada antes de la divulgación.

Coinciden la mayoría de los autores franceses en hacer hincapié en que a pesar de la ausencia de reconocimiento del derecho a la vida privada en la Constitución de 1958, el Consejo Constitucional la ha configurado como una libertad individual.

Robert y Duffau ${ }^{46}$ definen la vida privada como la conjunción de tres elementos, el respeto a unos comportamientos determinados de la persona (hablan del territorio de la persona entendida con un carácter físico), el anonimato y el respeto de las relaciones de la persona (respeto de las comunicaciones familiares y sentimentales).

44 Cita recogida de la obra de URABAYEN, Vida privada e información: un conflicto permanente, Eusansa, Pamplona, p. 15.

45 KAISER, P.: La protection de la vie privée, 2. ed., Económica, París, 1990, p. 10.

46 Robert, J., y Duffau, J.: Droit de l'Homme et libertés fondamentales, $6 .{ }^{a}$ ed., París, 1996, pp. 397 y ss. 
- Otro intento de definición conceptual de la intimidad lo constituye en Europa el Congreso de Juristas Nórdicos sobre el Derecho a la intimidad ${ }^{47}$. Parecen acudir las conclusiones de este Congreso a las del ordenamiento jurídico de Estados Unidos, y sobre todos a los orígenes del derecho a la intimidad, al definir a éste como «el derecho de una persona a ser dejada en paz para vivir su propia vida con el mínimo de injerencias externas". Pero en la duda, de que su definición fuese escueta, o dejara ámbitos del derecho fuera de ella, establecen una lista de los que consideran modos o formas de lesionar la intimidad, completando con ello la definición dada. De esta forma se acude a un concepto de intimidad basado en un ámbito de libertad, frente a la cual se establecen las siguientes prohibiciones o limitaciones de intromisión en la vida privada de la persona:

1. ${ }^{\text {a }}$ Toda injerencia en la vida privada o doméstica.

2. $\quad$ Todo atentado a su integridad física o mental, a su libertad moral o intelectual.

3. ${ }^{a}$ Todo atentado a su honor o a su reputación.

4. ${ }^{a} \quad$ Toda interpretación perjudicial dada a sus palabras o a sus actos.

5. ${ }^{a} \quad$ La divulgación intempestiva de hechos molestos en relación con su vida privada.

6. La utilización de su nombre, de su intimidad o de su imagen.

7. Toda actividad tendente a espiarle, vigilarle $u$ hostigarle.

8. ${ }^{\text {a }}$ La interceptación de su correspondencia.

9. a $^{2}$ La utilización malévola de sus comunicaciones privadas, escritas $u$ orales.

10. La divulgación de informaciones o comunicaciones recibidas por él bajo secreto profesional.

Como recoge López Díaz ${ }^{48}$, la importancia del contenido del congreso citado radica en la enumeración de contenidos de la esfera

47 Conclusiones. $1 .^{\mathrm{a}}$ parte. Punto 2. Estocolmo, 1967. Publicado en la Gazette du Palais, de 26 de julio del mismo año, en París.

48 Obra citada, p. 189. 
privada, para desde ahí, inducir un concepto más abstracto de intimidad.

- El Tribunal Europeo de Derechos Humanos establece una clara distinción entre lo íntimo y lo privado. A este último concepto le da una concepción más amplia que a la intimidad. De esta forma, para el T.E.D.H. sería demasiado restrictivo limitar la noción de vida privada a un círculo intimo, donde cada uno puede conducir su vida a su gusto $y$ excluir el mundo exterior. Si bien el contenido del art. $8 \mathrm{del} C E D H$, es bastante conciso, "Toda persona tiene derecho al respeto de su vida privada y familiar, de su domicilio y de su correspondencia", su interpretación no es en todo caso uniforme, sobremanera, en lo referente al ámbito concreto de la intimidad. Con todo, el TEDH viene ampliando de forma continua, el contenido de la vida privada, y el de la intimidad de manera especial (integridad psíquica y moral, vida sexual, ámbito de lo familia, domicilio, comunicaciones, protección de datos, entre los más significativos).

En España parece que no existen dudas, de que lo íntimo y lo privado, con ser ámbitos diferentes, son concurrentes. Lo íntimo sería un concepto estricto de dimensiones propiamente individuales, mientras que lo privado es un ámbito que engloba a lo intimo, pero que lo supera. Ésta es la postura del legislador español más reciente, el cual en la Exposición de Motivos de la Ley Orgánica de tratamiento automatizado de datos de carácter personal, en su apartado 1 establece la distinción entre intimidad y privacidad de forma clara: "Nótese que se habla de privacidad y no de intimidad: aquélla es más amplia que ésta, pues en tanto la intimidad protege la esfera en que se desarrollan las facetas más singularmente reservadas de la vida privada de la persona, la privacidad constituye un conjunto más amplio, más global de facetas de su personalidad...".

Pese a todo lo afirmado, otra parte de la doctrina entiende que la intimidad también puede ser interpretada en un sentido amplio, y que seria comprensivo de lo privado. Esta postura ha sido acogida en alguna ocasión por el Tribunal Constitucional, para quien «el derecho constitucional a la intimidad excluye de las intromisiones de los demás en la esfera de la vida privada personal y familiar de los ciudadanos ${ }^{49}$.

Desde nuestro modesto saber, cabe resolver esta confusión, en base a darle un significado concreto a cada uno de los términos y a rea- 
lizar una debida y correcta identificación de cada uno de ellos. Como hemos visto, y de ahi la utilidad de la exposición anterior al respecto de la configuración doctrinal y jurisprudencial de cada uno de los conceptos en los ordenamientos jurídicos más relevantes, para los norteamericanos todos los ámbitos o grados de intimidad (externo o interno) se engloban bajo el concepto de privacy. Por contra, en Europa, y sobremanera en España, los términos, ni etimológica, ni jurídicamente, tienen una igual significación. El Diccionario de la Real Academia Española ${ }^{50}$ define lo íntimo como "lo más interior o interno", y privado como lo que "se ejecuta a la vista de pocos, familiar y domésticamente...". El citado texto define lo privado, en su acepción segunda, como lo "particular y personal de cada uno". De ambas definiciones se extrae una conclusión identificable con las doctrinas ya manifestadas, es decir, lo privado es un ámbito más genérico que lo íntimo. Ahora bien, las necesidades de coherencia jurídica y el ordenamiento en concreto, abren nuevas puertas. De esta forma, en el ordenamiento jurídico español, parece más conveniente apartarse del anglicismo privacy, pese a que es frecuentemente utilizado en el ámbito de las relaciones del derecho y la informática, y acoger el concepto vida privada, por su mayor significación jurídica. Así, cuando en el ordenamiento jurídico español nos referimos a la intimidad, por analogia al término privacidad hemos referenciado tanto al derecho a la intimidad stricto sensu, como al derecho al honor, como al derecho a la propia imagen. En este sentido, es utilizado de forma frecuente el término privacidad por el Tribunal Constitucional, es decir, como un concepto globalizador de los derechos de la personalidad, pero no sustitutivo de cada uno de ellos. De forma concreta recogemos como ejemplo el contenido parcial de dos sentencias:

- S.T.C. 22/84, de 17 de febrero: "La inviolabilidad del domicilio constituye un auténtico derecho fundamental de la persona, establecido para garantizar el ámbito de privacidad de ésta...".

- S.T.C. $137 / 85$, de 17 de octubre: «...Derecho a la intimidad constitucionalmente garantizado por el art. 18 en relación con un área espacial o funcional de la persona precisamente en favor de la salvaguarda de su privacidad...n. De esta forma, hemos de entender que privacidad equivale a vida privada, en nuestro ordenamiento jurídico y en nuestro idioma. 
Esta no correcta utilización de términos está generalizada también en la doctrina, e incluso ha sido utilizada por el legislador, para erróneamente defender sus posturas políticas. Como hemos referenciado con anterioridad, Lucas Murillo ${ }^{51}$, pretende la incorporación en nuestro ordenamiento jurídico de un nuevo derecho, al que denomina "derecho a la autodeterminación informativa», por entender como insuficiente el contenido del art. 18.4 para la protección de los derechos de la personalidad frente a los ataques que puede sufrir la persona provenientes de los modernos medios tecnológicos, y en concreto de la informática.

Otros, como Davara Rodríguez ${ }^{52}$, entienden que «la protección de los datos personales está suficientemente protegida en las modernas legislaciones, mediante el derecho a la intimidad. Es cuando surge la informática, y la posibilidad de tratamiento automatizado de la información y su transmisión telemática cuando aparece una nueva relación entre datos y personas que necesitan ser protegidas más allá de las normas referentes a la intimidad. El derecho que se trata de proteger no es solamente el derecho a la intimidad, sino algo con mayor profundidad, que en los ordenamientos de ámbito anglosajón se ha dado en llamar privacy y que nosotros hemos traducido por privacidad". Sean suficientes estas dos muestras doctrinales, para el objeto de la argumentación, como ejemplo de la errónea utilización de los conceptos por parte del legislador. Conviene recordar también, las argumentaciones del Ministro de Justicia, en la defensa del contenido del proyecto de ley de la LORTAD en su tramitación parlamentaria. En ella se pretende llevar al ánimo de la Cámara (Congreso de los Diputados) la justificación del uso del concepto de privacidad. Así manifiesta: "... Creo que es una formulación singular de la propia Constitución, porque la intimidad y el honor ya están regulados en ella, pero aquí se habla de limitar el uso de la informática. Es, sin duda, un concepto nuevo el que aqui se está afrontando; es algo distinto, es una nueva dimensión que corresponde a unos nuevos medios tecnológicos y a un nivel de desarrollo que, seguramente, es algunos años después de la Constitución cuando empiezan a mostrar su auténtica dimensión y, en este sentido, también su auténtico peligro... el uso frecuente de medios informáticos amenaza con hacer que el perfil de cada cual pueda ser conocido por

51 LUCAS MURILLo, en su obra El derecho a la autodeterminación informativa, Tecnos, Madrid, 1990.

52 Davara Rodriguez, M. A.: La protección de datos en Europa, Madrid, 1998, p. 19. 
cualquier persona, en cualquier sitio y en cualquier momento, afectando por eso a una dimensión nueva» ${ }^{53}$. Esta misma concepción pasó a ser contenido de la Ley Orgánica 5/1992, la cual en su Exposición de Motivos ratifica la preferencia del uso del término privacidad sobre el de intimidad, y lo hace de la siguiente forma: "Nótese que se habla de privacidad y no de intimidad: aquélla es más amplia que ésta... la privacidad constituye un conjunto más amplio, más global, de facetas de su personalidad que, aisladamente consideradas, pueden carecer de significación intrínseca pero que, coherentemente enlazadas entre sí, arrojan como precipitado un retrato de la personalidad del individuo que éste tiene derecho a mantener en reserva. Y si la intimidad en sentido estricto ${ }^{54}$ está suficientemente protegida por las precisiones de los tres primeros párrafos del art. 18 de la C.E. y por la leyes que los desarrollan, la privacidad puede resultar menoscabada por la utilización de las tecnologias informáticas de tan reciente desarrollo».

Argumentamos lo impropio de la utilización del término privacidad, tanto por parte de la jurisprudencia, doctrina (aunque ésta es minoritaria), y legislador, en los siguientes apartados:

1. El derecho a la privacidad es un derecho que desconoce nuestra Constitución vigente. Ésta reconoce y establece los medios para que el legislador ordinario desarrolle los contenidos del derecho a la intimidad, al honor y a la propia imagen, ordena su vigencia y protección efectiva. Tampoco el Diccionario de la Real Academia Española de la Lengua reconoce el término.

2. En el supuesto de que, como manifiesta la Exposición de Motivos de la Ley Orgánica 5/1992, existiese la necesidad de protección ante nuevos peligros, podemos optar por dos caminos. O bien reformar la Constitución, e incluir este nuevo derecho; o bien tratar de solventar los peligros mediante ley. Pero ninguna de estas vias procede. El derecho a la privacidad no existe en el ordenamiento jurídico español, porque no se hace necesaria su existencia. El problema radica,

53 Diario de Sesiones del Congreso de los Diputados, n. ${ }^{\circ} 151$, IV Legislatura, 1991.

54 El subrayado es nuestro, con objeto de hacer notar la necesidad del uso de varios sentidos de intimidad. Se deduce que, para el citado, el sentido amplio es el derecho a la privacidad, y el sentido estricto es el derecho a la intimidad. 
como en tantos otros ámbitos, en la distinta atribución de significados a términos no propios del lenguaje español, o por la distinta significación o contenido entre los términos en el uso ordinario de la palabra, y en su utilización jurídica. Por ello creemos que conviene recordar el esquema de la terminología jurídica en el ámbito de los derechos de la personalidad en base a la siguiente representación:

\section{PÚBLICO}

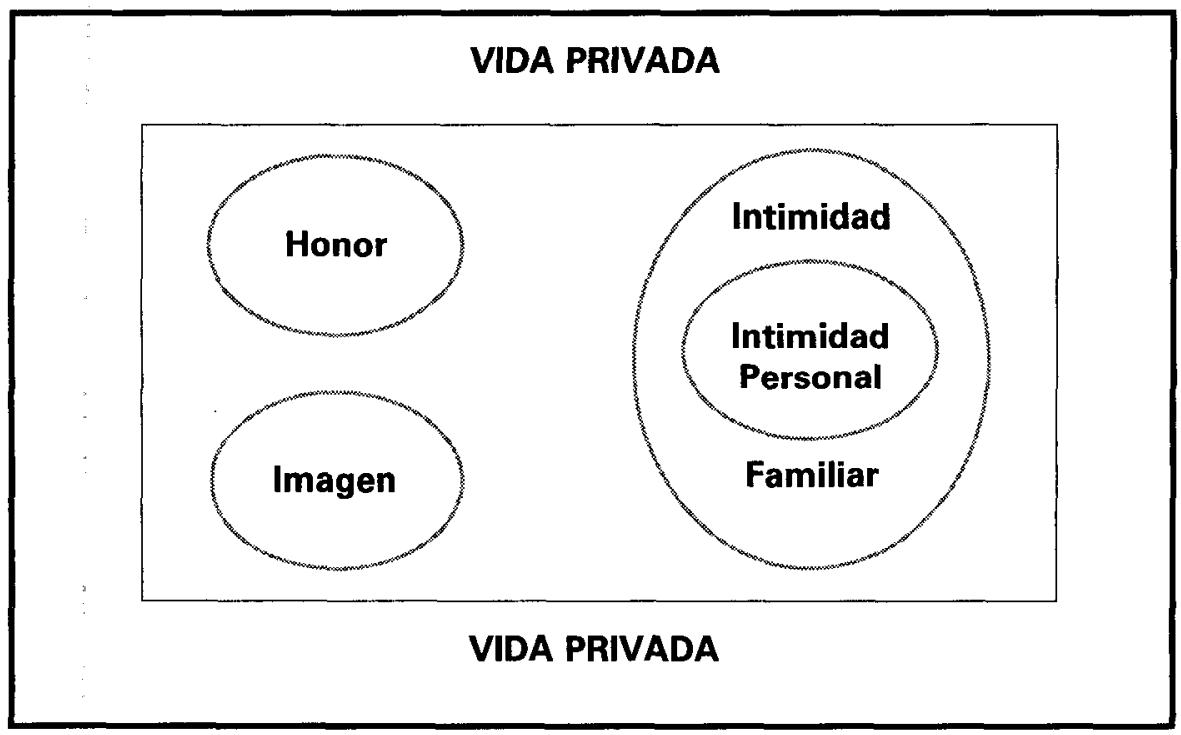

\section{PÚBLICO}

Cabe utilizar el concepto de privacidad referido a la vida privada, pero no identificarlo con un nuevo derecho que acoge aspectos tanto del derecho al honor como de la intimidad y propia imagen 55 , o como

55 Adviértase que la mayoría de la doctrina actual desconoce, en el ámbito de la vida privada, el concepto de privacidad, y referencian únicamente los derechos a la intimidad, al honor y a la propia imagen, y lo hacen entendiendo a ellos, como configuradores de un ámbito que denominamos vida privada. Mantienen esta configuración incluso cuando abordan el estudio del art. 18.4 de la C.E.; puede comprobarse ello, entre otras, en las siguientes citas: 
lo utiliza el legislador y los tribunales europeos, que referencian intimidad como vida privada, pero respetando el contenido esencial del derecho a la intimidad.

En todo caso, hemos de reconocer, con rotundidad, que no existe necesidad de reconocer nuevos derechos. Las posibilidades de lesión son muchas, y más aún los medios para lesionar derechos de la personalidad, pero el bien jurídico a proteger sigue siendo la intimidad, el honor o la propia imagen, o en última instancia, la dignidad de la persona. Esta protección existe a nivel constitucional y legislativo. Ahora bien, será en el ámbito inferior de la pirámide normativa, y en concreto será el Reglamento que desarrolle el contenido de la Ley Orgánica 5/1992 o la adecuación de ésta a los imperativos de la normativa europea, y de forma concreta a las Directivas 95/46 CE y 97/66 CE, quien habrá de prever los medios para que no se produzcan las intromisiones o vulneraciones de los derechos que venimos estudiando.

3. Conviene recordar que, a pesar de que la Exposición de Motivos de la L.O. 5/19927, pretende la configuración del derecho a la privacidad, el contenido de su artículo primero lo desdice con rotundidad. El literal del mismo es: "La presente Ley Orgánica, en desarrollo de lo previsto en el apartado 4 del artículo 18 de la Constitución, tiene por objetivo limitar el uso de la informática y otras técnicas y medios de tratamiento automatizado de datos de carácter personal para garantizar el honor, la intimidad personal y familiar de las personas fisicas y el pleno ejercicio de sus derechos". Además de ello, el articulado de la citada ley no usa el término de privacidad en ninguna ocasión.

4. ${ }^{\circ}$ Por último, de seguir las indicaciones de la Exposición de Motivos de la LORTAD, tendremos conciencia de la definición de privacidad, pero hemos de seguir utilizando distintas concepciones de intimidad (en su sentido amplio, o en el sentido restringido), con lo que en lugar de clarificar conceptualmente los derechos que estudiamos, la consecuencia es que enturbiaríamos su significación. Cada usuario del

Álvarez Conde, E.: Curso de Derecho Constitucional, vol. I, Madrid, 1993, pp. 296 a 298.

Torres del Moral, A.: Principios de Derecho Constitucional Español, 4. ${ }^{a}$ ed., Madrid, 1998, pp. 300 a 302.

Pérez Royo, J.: Curso de Derecho Constitucional, Madrid, 1994, pp. 256 a 260. Jorge de Esteban y González-Trevijano: Curso de Derecho Constitucional Español II, vol. II, Madrid, 1993, pp. 107 a 110.

Rodriguez Zapata, J.: Teoría y práctica del Derecho Constitucional, Madrid, 1996, pp. 338 y 339 . 
término le dará una interpretación, con lo que no sabremos a qué aspecto de la intimidad se refiere o qué significado quiere darle.

Cabe dar una explicación a esta circunstancia tan poco jurídica, como es el que se utilice para una delimitación tantos sustantivos. Si el derecho se caracteriza por la atribución de un significado único a los términos, empleando para ello conceptos diferentes, sean ellos coincidentes o no con su significado en el uso coloquial, en el ámbito del derecho a la intimidad esta circunstancia se desvanece. Ello es consecuencia de que el jurista, sobre todo en el ámbito de la informática, se sumerge en un mundo de conceptos de formulación rápida, de traducciones o adaptaciones de términos a nuestro idioma que no tienen un encaje concreto en cuanto a su significado en el ordenamiento jurídico español. Además de ello, del ámbito de la intimidad informática se ha querido hacer un mundo para iniciados, un subordenamiento jurídico, con circunstancias que se quieren hacer singulares. De esta forma se habla ya de delitos informáticos, de contratos informáticos, de derecho mercantil informático, etc.

No cabe duda de lo novedoso de la influencia de las tecnologías en nuestra vida y entorno social, y también del cambio que supondrán, pero todos los ordenamientos jurídicos han sabido y podido absorber, con mayor o menor fortuna, en sus estructuras y normas, estas nuevas circunstancias. De esta forma, el derecho tiene los mecanismos necesarios (en su configuración básica) para hacer frente a estas novedades. La simplificación consiste en que se da una actuación lesiva y antijurídica, para las cuales el ordenamiento jurídico establece unos mecanismos de protección y de resarcimiento. Lo que se lesiona no es algo novedoso (la dignidad, la vida privada, los derechos fundamentales), la nueva circunstancia viene dada por los medios de hacerlo o por los útiles para llevarlo a efecto. Realizada la lesión se pone en funcionamiento el entramado legislativo y judicial existente para paliarlo. Por tanto lo único que le cabe al legislador es ensanchar la norma o adecuarla para contemplar los nuevos medios. Y en la mayoría de las ocasiones, como ocurre con la protección de la intimidad frente a la informática o de forma genérica con las telecomunicaciones, esta tarea la realiza antes el legislador europeo o internacional que el nacional. Con ello, éste último únicamente ha de transponer la normativa.

Como fácilmente puede deducirse, para realizar esta tarea no es necesario inventar nuevos derechos, atribuir distintos significados a los derechos o términos ya existentes, importar términos de otros ordenamientos jurídicos que no tienen traducción posible ni pretender en todo caso hacer de una novedad tecnológica un sistema jurídico. 


\section{LOS DERECHOS DE LA PERSONALIDAD COMO LÍMITE DE LA INFORMÁTICA}

\section{Aspectos previos}

El conocimiento que el Estado ha tenido históricamente del ciudadano es sumamente escaso hasta la Revolución Francesa de 1798. Suele concretarse en aspectos tributarios o de prestación de determinados servicios, con un ámbito muy localizado y con una escasa capacidad de difusión e intercambio. Era mayor, como apunta Frosini56, el ejercido por «...la Iglesia quien, por el contrario, llevaba un registro de sus fieles, a partir de la inscripción de su bautismo, matrimonio, defunción, etc.». Tampoco es de tener en cuenta, en estas épocas, la capacidad de intromisión del propio ciudadano en la íntima parcela de otro cualquier ciudadano. Es el Estado, fundamentalmente por la necesidad estadística, quien primero va a suscitar la problemática del acopio de datos y su influencia en los reconocidos ya derechos de la personalidad.

Las nuevas tecnologías, al posibilitar la racionalización, simplificación, celeridad y seguridad de las prácticas administrativas y de recopilación de datos, se presentan como una amenaza ante el ciudadano, ya que el uso de los modernos medios electrónicos, estén en manos de quien estén, contraen el riesgo de injerencia en la vida privada, tienen implícita la posibilidad de lesionar derechos de la personalidad. Con todo, no podemos establecer como única visión de los modernos medios de tecnología, sólo la negativa. Estos no cabe duda que ofrecen un aspecto sumamente positivo en la actividad del ser humano, racionalizando y suprimiendo laboriosos trabajos, y sobre todo rompiendo, tanto en el ámbito laboral como social, las barreras del espacio y el tiempo. Baste como ejemplo significativo de este aspecto positivo el art. 45 de la Ley 30/1992, de Régimen Jurídico de las Administraciones Públicas y del Procedimiento Administrativo Común, que abrió el camino de la informática en un ámbito como la actuación administrativa, que estaba y está parcialmente sometido a fuertes rigideces procedimentales. El desarrollo de este artículo, concretado en el Real Decreto 263/1996, de 16 de febrero, es un ejemplo del avance y adecuación de las nuevas actividades, tanto del Estado como de los ciudadanos a los

56 Frosini, V.: "Bancos de datos y tutela de la persona”, Revista de Estudios Políticos (N.E.), n. ${ }^{\circ} 30$ de 1982, p. 68. 
nuevos sistemas de comunicación e interacción. Como la propia Exposición de Motivos del citado Decreto establece, "constituye un anacronismo la concepción de la Administración como una organización basada en la burocracia escrita, y asentada sobre antiguos principios de registros públicos excesivamente formalistas $y$ archivos constituidos por inmensos legajos de papel».

La informática, debidamente ordenada $y$ accesible, constituye indefectiblemente poder, y no cabe duda de que al Estado le es necesaria determinada información para cumplir sus fines. Pero no es menos cierto que un uso abusivo o incontrolado de ella puede minar el funcionamiento de cualquier Estado. El mismo riesgo de acumulación de datos, al que está sometido el individuo por la acción del Estado, es el de la acumulación de datos por parte de otros ciudadanos.

Partiendo del principio democrático de que el poder ha de estar necesariamente sometido al Derecho, es fácil deducir una solución incontestable, es decir, sometamos a la norma, la actividad que de esa información susceptible de lesionar derechos, pueda realizar tanto el Estado como los particulares. Esta solución está exenta de toda problemática o complejidad jurídica. Ahora bien, los problemas surgen en su aplicación práctica, en el desarrollo efectivo de tales medidas.

\section{El planteamiento constitucional y legislativo}

La C.E. de 1978 no ha sido ajena a la importancia que de forma genérica la tecnología, y de forma concreta la informática, está produciendo en las relaciones sociales y en la persona. Esta situación de la que ahora somos conscientes, había sido anticipada por mentes lúcidas, como es el caso de Ruiz-Giménez ${ }^{57}$, que ya en 1969 manifestaba lo siguiente: "Si la intimidad es un valor fundamental del ser del hombre, uno de sus bienes básicos, no cabe duda de que ha de reflejarse en la existencia colectiva como un derecho natural o fundamental, que el ordenamiento jurídico debe proteger contra cualquier violación por parte de los demás hombres, y más aún de las instituciones o comunidades que éstos forman".

57 Ruiz-Giménez, J.: «El derecho a la intimidad», Cuadernos para el Diálogo, n. ${ }^{\circ} 66$ de 1969, p. 10. 
La predicción del citado autor, era anterior incluso, a inquietudes semejantes en otros ordenamientos. Ninguna de las constituciones de ese momento en Europa, había previsto la posible vulneración de derechos de la persona por medio o a través de los modernos medios tecnológicos. Era frecuente, cuando en contadas ocasiones surgían los conflictos, acudir a laboriosas interpretaciones doctrinales o jurisprudenciales de determinados contenidos de las constituciones. Hasta 1970, en el Land de Hesse, no es dada una normativa concreta de protección. En 1974 surge en Estados Unidos la Privacy Act. Pero la primera ley realmente previsora de un contenido y garantías al respecto de la protección de la privacidad y sobre el control de los bancos de datos no se dará hasta 1973, en el Parlamento sueco58. En el mismo año, el Consejo de Europa adopta la resolución $n .^{\circ} 22$ sobre «la protección de la vida privada de las personas físicas respecto a los bancos electrónicos de datos en el sector privado" y en 1974 se amplía a los datos del sector público. Estas regulaciones se constituyen en un adelanto de varias circunstancias hasta ahora desconocidas: En primer lugar, se constata que ha surgido una nueva necesidad, que tiene su origen en la vulneración de derechos individuales y sociales por parte de los modernos ingenios tecnológicos; el segundo aspecto lo constituye la preocupación de todos los ordenamientos jurídicos por establecer el alcance $y$ los límites que la norma ha de tener para garantizar los derechos ya vigentes, y de qué manera pueden formularse aquellos que protejan la nuevas intromisiones. Esta fase se revela conflictiva tanto en la doctrina, como en la actividad del legislador, además de que existe una conciencia social pujante, que constata la inseguridad juridica; una última fase, en la que nos encontramos, viene caracterizada por normas de carácter internacional con una formulación genérica, $y$ otras de ámbito nacional más concretas. Entre estas últimas se aprecia la necesidad, dado que los medios tecnológicos no conocen de barreras (ni jurídicas ni políticas), de unificar y coordinar sus contenidos y pretensiones, dificultad que no se solventa hasta después de 1995 (Directiva 95/46).

Estos considerables antecedentes legislativos constituian una importante premisa de carácter jurídico y político para un acercamiento serio a las relaciones entre el ciudadano y la Administración Pública, que tuviese en cuenta adecuadamente el progreso tecnológico. Como afirma Frosini 59 , «a mediados de los años setenta, ya era tiempo para 
un reconocimiento jurídico de la nueva forma del derecho a la discreción sobre datos que de manera sintética llamamos libertad informáti$c a$, al nivel más alto de la conciencia política y jurídica». De esta forma, la Constitución de Portugal de 1976 enuncia por primera vez con rango constitucional, el principio por el cual cada ciudadano tiene el derecho a conocer sus datos personales recopilados en los bancos de datos, $y$ de pretender su corrección y actualización (art. 35). La incidencia de este artículo, así como las diversas leyes europeas sobre protección de datos personales influyeron en la idea del constituyente sobre la necesidad de regular constitucionalmente un ámbito tan significativo ya en 1978, como el de la informática. Por ello, en el borrador y en el Anteproyecto Constitucional se relataba el asunto de la siguiente manera: "La ley limitará el uso de la informática para garantizar el honor y la intimidad personal y familiar de los ciudadanos ${ }^{60}$. Este texto, con algunas modificaciones, pasó a ser el art. 17 del Informe de la Ponencia. En la Comisión del Congreso, surgieron dos posturas al respecto del contenido del citado artículo; una primera ${ }^{61}$ pretendía la supresión del apartado $4 .^{\circ}$ del art. 17 (art. 18.4 vigente), entendiendo que la protección que se proporcionaba con el contenido del apartado primero (art. 18.1 actual), preveía cualquier tipo de atentado contra tales facultades. También se consideraba inoportuno, hacer una mención expresa a la informática y no a otra serie de técnicas o medios que podían vulnerar la intimidad, el honor o la propia imagen. La segunda postura62, consideraba conveniente hacer mención expresa de la informática, pero haciendo extensiva la tutela frente a cualquier derecho, por un uso indebido, y no sólo a los derechos de la personalidad, siendo esta segunda postura la que tuvo reflejo constitucional en el artículo 18.4 .

De esta forma, la C.E. de 1978, siguiendo la intencionalidad, que no la literalidad de la Constitución Portuguesa de 1976, regula la utilización informática. Establece, como afirma Álvarez Conde ${ }^{63}$, que «el reconocimiento de estos derechos fundamentales efectuado por el art. 18.1 debe ser considerado como una manifestación concreta del derecho a la integridad moral del art. 15 de la C.E.". De esta forma tangencial, el art. 18.4 de nuestra norma fundamental, remite al desarrollo legislativo la limitación del uso de la informática para evitar la colisión

$60 \quad$ Anteproyecto constitucional. B.O.C. de 5 de enero de 1978.

61 Defendida por el Sr. Sancho Rof (UCD).

62 Sustentada por el Sr. Gastón Sanz (PSOE) y apoyada por el Sr. Roca Junyent (Minoría Catalana). p. 294.

63 Álvarez Conde, E.: Curso de Derecho Constitucional, vol. I, Madrid, 1992, 
directa entre el derecho a la intimidad con las necesidades informáticas, fundamentalmente de los poderes públicos.

También tiene implicaciones informáticas el art. 105.b de la C.E., el cual posibilita el acceso de los ciudadanos a los archivos y registros administrativos, salvo en lo que afecte a la seguridad y defensa del Estado, averiguación de los delitos y la intimidad de las personas.

Afirma Frosini64 que "la nueva relación que se estableció entre los ciudadanos, y entre los ciudadanos y el Estado... planteó de nuevo el problema fundamental de cómo reglamentar la relación entre poder y libertad", ante ello, sigue manifestando el autor, se pueden dar dos posturas; "una seguida por la legislación americana que se concreta en el principio de que todo está permitido, salvo lo que está prohibido, $y$ otra cuyo representante principal es Alemania, la cual entiende que cualquier actividad relativa al procesamiento de datos personales está prohibida, salvo cuando está permitida».

No parece descaminado pensar que la regulación que afecta al derecho de la intimidad en España, está inmersa en la segunda de las dos opciones citadas. No cabe duda, que el constituyente perdió, una magnífica oportunidad de una ex novo y original regulación al respecto del tratamiento automatizado de datos. Significativo de lo manifestado, es el distinto enclave constitucional de los dos artículos citados. Por una parte, el art. 18.4, se inserta dentro del núcleo dogmático de la Constitución (Sección Primera del Capítulo Segundo del Título Primero), correspondiéndole, por tanto, el mayor grado de protección. Por contra, el contenido de mayor virtualidad, en el ámbito de salvaguarda de los datos, es decir el art. 105.b, se sitúa en la parte orgánica de la C.E. Quedando con ello difuminados sus elementos garantizadores $y$ protectores. Además, su contenido no deja de identificarse con el del art. 20.1.d). Con todo, el reconocimiento constitucional, que es leve e inconcreto, queda pendiente de una normativa posterior, que a pesar de ser orgánica, en virtud del art. 81 del propio texto, queda apartada del carácter constitucional.

En definitiva, y para finalizar este apartado, no podemos dejar de tener en cuenta las afirmaciones del Tribunal Constitucional, que a nuestro entender resumen de forma acertada la intencionalidad del constituyente, cuando manifiesta al respecto del art. 18.4, que «...De este modo, nuestra Constitución ha incorporado una nueva garantía 
constitucional, como forma de respuesta a una nueva forma de amenaza concreta a la dignidad y a los derechos de la persona, de forma en último término no muy diferente a como fueron originándose e incorporandose históricamente los distintos derechos fundamentales..." ${ }^{65}$.

\section{El tratamiento automatizado de datos de carácter personal}

Es carácter innato al Derecho el ir dando soluciones a los problemas sociales que se plantean, dando respuesta jurídica a una necesidad social. En las relaciones entre informática y Derecho, la aceleración que se ha producido es muy significativa, y hasta en ocasiones impropia de la naturaleza de las normas, que pretenden de forma genérica su permanencia en el tiempo. Así pues, se habla ya de diversas generaciones o fases en la garantía jurídica de los datos, a imagen y semejanza de las generaciones de ordenadores y de las denominadas generaciones de derechos. De esta forma, pueden distinguirse tres fases con claridad: una primera generación requiere la autorización previa de los bancos de datos; la segunda generación coincide con la garantía de los que con posterioridad han sido denominados datos sensibles, dada su incidencia en los derechos de la personalidad; y por último, una tercera generación, que reconoce la imposibilidad de un control previo de los equipos $y$ de un control estático de los datos, y que por tanto tiene que prevenir su potencialidad y funcionalidad.

En España, hasta 1992, se articuló un sistema que sin duda no obedecía a ninguna de las generaciones mencionadas. La protección del contenido del art. 18.4 de la C.E. se brindaba en base a la Ley Orgánica 1/1982. Se pensaba que con la protección civil del derecho al honor, la intimidad y la propia imagen, era suficiente para solventar las intromisiones o violaciones que pudiera producir la informática. Por ello, la Disposición Transitoria Primera de la citada ley, establecía que «...en tanto se promulgue la normativa prevista en el art. 18, apartado $4 .^{\circ}$, de la Constitución, la protección civil del honor y la intimidad personal y familiar frente a las intromisiones ilegítimas derivadas del uso de la informática se regulará por la presente ley". Pese a ello, y como acertadamente resume Lucas Murillo, “la Ley Orgánica 1/1982 solamente protege lo que podriamos llamar el ámbito más estricto de la in- 
timidad, pero no sirve para impedir la captación, el acopio, revelación y transmisión de informaciones personales que no necesariamente han de pertenecer a ese reducto último de la vida privada. Por lo demás, no es útil para brindar al afectado medios que le permitan conocer qué datos relativos a su persona usan terceros, ni para permitirle rectificar los que sean inexactos o cancelar los que carezcan de toda relevancia actual» 66 .

Centrados ya en la virtualidad protectora del art. 18.4 de la C.E., de nuevo surgen las discrepancias doctrinales de la concepción que de este precepto debe realizarse. Como bien sabemos, el derecho a la intimidad informática ve la luz a través de la sentencia del Tribunal Federal Alemán de 15 de diciembre de 1983, por la cual se adecúa el concepto de derecho a la autodeterminación informativa. En España, Lucas Murillo ${ }^{67}$ introduce el término vía art. 18.4 de la C.E., manifestando que el derecho a la intimidad normalmente implica el poder jurídico de rechazar intromisiones ilegítimas en la esfera protegida, y correlativamente, determinar de forma libre, la propia conducta. Es un típico derecho de defensa. Pero para el autor que venimos resumiendo, la técnica de protección de datos, es más compleja. Por ello, es necesario abandonar el concepto clásico de derecho de intimidad y optar por la creación de uno nuevo (el derecho a la autodeterminación informativa), que tendría como objeto preservar la información individual, frente a su utilización incontrolada. De esta forma el derecho a la intimidad se subdividiría en una intimidad física o clásica, y en una intimidad informativa, entendida ésta, como el derecho a determinar cómo y en qué medida se puede comunicar a otros información sobre uno mismo.

Pese a todo, no parece ser ésta la visión mayoritaria de la doctrina ni de la jurisprudencia, que entienden al derecho a la intimidad como universalmente aplicable frente a cualquier tipo de agresión, violación o intromisión, provenga ésta de donde provenga. Tampoco faltan autores ${ }^{68}$ que entienden la construcción del Tribunal Federal Alemán como propia de un sistema, cuya Carta Magna no recoge de forma expresa el derecho a la intimidad. De esta forma, la construcción jurídica es lógica en Alemania, pero no lo es tanto en un sistema como el es-

66 Lucas Murillo de la Cueva, P.: Informática y protección de datos personales, Centro de Estudios Constitucionales, Madrid, 1993, p. 17.

67 LuCAS MuRILLO DE LA CUeVA, P.: El derecho a la autodeterminación informativa, Tecnos,Madrid, 1990, p. 117 y ss.

68 Ruiz Miguel, en obra citada, p. 95. 
pañol en que se recogen de forma expresa por la Constitución diversas manifestaciones del derecho a la personalidad, como son el honor, la propia imagen y la intimidad personal y familiar.

Resumiendo, no podemos extraer otra interpretación del contenido del artículo 18.4, que no sea la de un reconocimiento expreso de la posibilidad de vulnerar la intimidad mediante la informática. Ello tiene un pleno acoplamiento en nuestro ordenamiento jurídico en cuanto a concepción, idea y grado de garantía del derecho. En definitiva, el derecho a la intimidad informática es una extensión de un derecho raíz y con pleno asentamiento en el derecho a la intimidad personal y familiar, con implicaciones en el derecho al honor y a la propia imagen.

De esta forma, parece claro que todo ordenamiento jurídico ha de establecer un umbral de tutela de la información personal frente a los peligros que representa la informática. Estos principios básicos fueron establecidos por la Comisión de Estudio sobre la Protección de la Intimidad ${ }^{69}$, los cuales se resumen en tres apartados básicos:

1. Todo individuo tiene derecho a acceder a la información personal que le afecte, $y$ especialmente a aquella que se encuentra en bancos de datos informatizados.

2. Todo individuo ha de tener la posibilidad y el derecho a controlar, de forma razonable, la transmisión de la información personal que le afecte.

3. La norma ha de regular necesariamente, como garantía del derecho a la intimidad:

- El tiempo durante el que se pueden conservar los datos personales.

- La determinación de los fines a que obedece la creación del fichero.

- Garantías para hacer efectiva la calidad de los datos personales (veracidad, integridad y actualidad).

- Prohibición de la revelación de datos personales.

Partiendo de la idea de que utilizamos el concepto de protección de datos, para referirnos a la uprotección juridica de las personas en lo

69 Comisión creada en Estados Unidos en 1974, en virtud del contenido de la Privacy Act del mismo año. 
que concierne al tratamiento automatizado de sus datos personales "70, llegamos a la conclusión de que la pretensión primera del legislador ha de pasar necesariamente por proteger a las personas ante el manejo o manipulación, no autorizada, de sus datos personales, siempre que los datos sean susceptibles de un tratamiento informático.

También se nos hace necesaria la definición nítida del concepto de dato. Así identificamos dato con documentación, con un contenido aislado y sin relación con nada. Si sometemos el dato o datos a un tratamiento o adecuación a un fin, con objeto de obtener un resultado concreto, el dato se convierte en información.

De esta forma, llegamos a la conclusión, que toda protección de datos se resume en tres características básicas:

1. Los datos han de ser susceptibles de tratamiento automatizado. Ello es debido a que, como indica la Exposición de Motivos de la LORTAD, hasta ahora "las fronteras de la privacidad estaban definidas por el tiempo y el espacion, y los modernos ingenios pueden traspasar esas barreras.

2. ${ }^{\text {a }}$ Ha de existir la posibilidad de identificar el resultado del tratamiento de datos con el titular del mismo.

3. El acceso y utilización de los datos ha de estar regulado.

Pues bien, a estos tres aspectos dedicamos las siguientes páginas, utilizando como vía de análisis la regulación existente.

\subsection{Convenio de 28 de enero de 1981 del Consejo de Europa ${ }^{71}$}

Como hemos apuntado, la inquietud de las organizaciones supranacionales, por el respeto a los derechos de la personalidad, asi como por las disfunciones sociales que los nuevos medios tecnológicos pueden producir, tuvo su plasmación en el Convenio n. $108 \mathrm{del}$ Consejo de Europa. Este texto establece una serie de principios básicos pa-

70 Ésta es la definición que ofrece Davara en su obra Derecho Informático, Aranzadi, Madrid, 1993, p. 49.

71 Ratificado por España el 27 de enero de 1984 (B.O.E. n. ${ }^{\circ} 274$, de 15 de noviembre de 1985). 
ra la protección de datos, señala criterios que regulan su flujo y crean un Comité Consultivo a quien se encomienda la formulación de propuestas para mejorar la aplicación del Convenio.

Su contenido puede resumirse en base a los principios que establece, los cuales se entienden como imperativos para aquellos Estados que lo ratifican. Tienen la genérica pretensión, como indica la Introducción del propio Convenio de «reforzar la protección de datos, es decir, la protección jurídica de los individuos con relación al tratamiento automatizado de datos de carácter personal que les conciernen".

Vista la pretensión final del Convenio, analizamos los principios en los cuales se resume su contenido ${ }^{72}$.

- Principio finalista: la finalidad justificativa de la creación del banco de datos debe estar definida y habrá de darse antes de ponerse en funcionamiento, con objeto de que sea constatable en todo momento:

a) Si los datos recogidos y registrados tienen relación con el objetivo por el que fue creado el fichero (pertinencia de los datos).

b) Si la información se utiliza para un fin distinto del propio banco de datos (principio de utilización no abusiva).

c) Si el tiempo durante el que se conservan los datos no excede del que normalmente se necesita para conseguir la finalidad para la cual fueron registrados (principio del derecho de olvido).

- Principio de lealtad: La recopilación de información ha de realizarse por medios lícitos.

- Principio de exactitud: Todo responsable de un banco de datos tiene la obligación de comprobar la exactitud de los datos registrados. Asimismo, es responsable de su actualización.

- Principio de publicidad: Ha de existir un registro público de los ficheros automatizados.

72 Seguimos en este resumen de principios, la exposición de Louis JOINET, en su obra Informatique et droits de l'homme. Recueil des Cours. Institute Internacional des Droits de l'Homme, Estrasburgo 2-27 julio de 1984, pp. 6 y ss. 
- Principio de acceso individual: Cualquier persona tiene derecho a conocer si los datos que le conciernen son objeto de tratamiento informatizado $y$, si así fuera, a obtener copia de ellos. También cabe la posibilidad de rectificación si los datos fueran erróneos o inexactos.

- Principio de seguridad: Las bases de datos han de estar protegidas en todos sus ámbitos.

A estos principios recogidos en el Capítulo II del Convenio, hay que añadir el contenido en el artículo 6, que especifica que ulos datos de carácter personal que revelen el origen racial, las opiniones políticas, las condiciones religiosas $u$ otras convicciones así como los datos de carácter personal relativos a la salud o la vida sexual, no podrán tratarse automáticamente a menos que el derecho interno prevea garantías apropiadas. La misma norma regirá en el caso de datos de carácter personal referentes a condenas penales".

Además de todo lo manifestado, el texto expresa el compromiso de las partes contratantes de establecer un régimen de recursos y sanciones que hagan efectivo estos principios.

Con el contenido del Convenio que analizamos, quedaba ya en 1981 establecido el marco genérico de protección de la persona, frente a las posibles intromisiones en su intimidad, o la lesión de derechos de la personalidad de forma más genérica, por parte de la informática. $\mathrm{Pe}$ se a todo, la evolución, en este aspecto tan significativo de las relaciones sociales, necesita de más desarrollos normativos, tanto en el ámbito internacional como en el de cada uno de los Estados.

\subsection{Acuerdo de Schengen de 14 de junio de $1985^{73}$}

El citado Acuerdo tiene como centro de su contenido disposiciones de los órganos de la Unión Europea relativos a la supresión gradual de los controles en las fronteras comunes. No obstante, los artículos 7 y 9 del citado Acuerdo pretenden la coordinación entre Estados, al efecto de controlar y facilitar "los datos que puedan ser de interés para las otras partes en la lucha contra la criminalidad" (art. 9). En de- 
finitiva, el Acuerdo de 1985 es un elemento de coordinación interestatal, que afecta al tratamiento y protección de datos, aunque no tenga un carácter concreto como lo tiene el Convenio de 1981, o la Directiva 95/46 del Parlamento Europeo y del Consejo, al respecto del tratamiento de datos personales.

El Acuerdo de Schengen no deja de ser un paso más en el contenido del art. 12 del Convenio de 1981, en virtud del cual se regula el flujo transfronterizo de datos de carácter personal. Ello tendrá su reflejo en los artículos 32 y 33 de la LORTAD, donde bajo el título de movimientos internacionales de datos, se preceptúa la prohibición de cesión de datos a países que no establezcan un nivel de protección igual al que establece la LORTAD, si bien se regulan excepciones. Con posterioridad, en 1995, la Directiva establecerá en su art. 25, idéntico contenido al respecto de la cesión internacional de datos a terceros países no integrantes de la Unión Europea.

En definitiva, con estos cuatro ámbitos de protección se establece la garantía, recogida ya en el ámbito nacional, de que los datos, salvo autorización expresa y concreta del interesado, no sufrirán un tratamiento indebido en otros países.

\subsection{La ley orgánica 5/1992 de tratamiento automatizado de datos de carácter personal}

Con la aprobación de esta norma, el legislador cumplía el mandato constitucional contenido en el art. 18.4, aunque nótese que con cierto retraso (de 1979 a 1992). Su contenido no ha dejado de ser polémico, y objeto tanto de disputa doctrinal como política. Prueba de lo segundo son las diversas opiniones y valoraciones sobre su efectividad $y$ eficacia como norma, y de lo primero, los distintos recursos de insconstitucionalidad planteados ${ }^{74}$.

74 La Generalitat de Cataluña considera inconstitucional el art. 5.3, dado que su grado de indeterminación vulnera el principio de seguridad jurídica del art. 9.3 de la C.E., por lo cual planteó recurso de inconstitucionalidad. El Parlamento de Cataluña plantea su recurso en base a que el art. 18.4 de la C.E. no establece, en puridad, un derecho fundamental, sino que, por la vía de la limitación de una actividad, la informática configura una garantía específica del derecho expresado en el art. 18.1, pero también de forma genérica, del conjunto de los derechos de la persona. El Defensor del Pueblo y el Grupo Parlamentario Popular impugnan los artículos $21.1,21.2$ y 22.2 . 


\subsubsection{Objeto de la ley}

Pese a que el art. 18.4 en su inciso final, establece la protección del uso de la informática frente al pleno ejercicio de los derechos, no cabe duda, de que la finalidad originaria y esencial de la LORTAD, se establece "en hacer frente a los riesgos que para los derechos de la personalidad puede suponer el acopio $y$ tratamiento de datos por medios informáticos... $)^{75}$. Como consecuencia de ello, la LORTAD no está Ilamada a solventar o prevenir todos y cada uno de los derechos de los que un ciudadano puede ser titular, sino que lo es fundamentalmente en aquellos que la informática puede lesionar, es decir, los referidos a la personalidad. Pero tampoco está orientado el contenido de la Ley Orgánica que estudiamos a todos los derechos de la personalidad. Se deduce de una lectura somera del texto, que el derecho a la propia imagen es absorbido, desde la perspectiva de la protección de datos por el derecho al honor, y éste se protege con levedad. Así cabe la prevención del honor, únicamente, en la medida que el acopio de datos y su adecuación y ordenación, pueden ofrecer el perfil de una persona, o configurar una determinada reputación o fama que puede verse lesionada.

Así pues, el objeto de protección primordial en la LORTAD no es otro que el de la intimidad, pero no entendida en un sentido estricto, como referida particularmente a lo físico, a lo más interior del individuo. El derecho a la intimidad, tal y como lo hemos configurado en páginas anteriores, en su relación con el tratamiento de datos, ha de adquirir un sentido amplio, globalizante, que incluya tanto aspectos relacionados con el honor como con la intimidad, así como con la propia imagen.

En base a lo manifestado, la norma de 1992 tutela la intimidad mediante un mecanismo de protección típico, que se fundamenta en esencia en cuatro aspectos:

1. $\quad$ Se prohíbe una conducta, la que implica intromisión en un ámbito protegido (intimidad).

2. La vulneración de esta prohibición lleva aparejada unas consecuencias jurídicas, unas medidas represivas.

3. La intromisión se considera como un perjuicio que ha de ser resarcido. 
4. En algunas ocasiones se pretende, desde la perspectiva de la prevención, dar soluciones a esas intromisiones, articulando medidas de protección futuras.

En base a estos cuatro apartados se articula la defensa de la intimidad del individuo. Ello hemos de incardinarlo en un contexto jurídico que le da sentido y medios materiales. A ello hemos de añadir las facultades que se le ofrecen al perjudicado, de revisión, rectificación, cancelación $y$ de petición del resarcimiento de los daños que le pueda ocasionar un tratamiento indebido de los datos. De esta forma, como afirma Lucas Murillo, «el bien jurídico subyacente es la libertad informática o la autodeterminación informativa, y consiste, sencillamente, en el control que a cada uno de nosotros nos corresponde sobre la información que nos concierne personalmente, sea íntima o no para preservar, de este modo, y en último extremo, la propia identidad, nuestra dignidad y libertad $n>7$.

\subsubsection{Rango de la ley}

Establece el art. 81 de la C.E. que «son leyes orgánicas las relativas al desarrollo de los derechos fundamentales y las libertades públicas». Dado el contenido del art. 18, y su ubicación en la parte dogmática de la Constitución, no le cabe al legislador otra opción que atender el mandato constitucional. Como hemos visto, pueden existir dudas o interpretaciones al respecto de cuál es en esencia el bien juridico protegido o cuál es el ámbito y delimitación exacta del concepto de intimidad. Pese a ello, no caben dudas que el desarrollo de unos derechos tan importantes y esenciales en la configuración de la libertad del individuo, como son los derechos de la personalidad, requieren una normación de rango superior, como así lo exige la C.E. Además de ello, la doctrina en pleno es consciente del alumbramiento de un nuevo derecho (la intimidad), de una configuración garantista novedosa en nuestro ordenamiento jurídico para adecuarse a las necesidades surgidas, y ello se hace, en buena razón jurídica, con un texto de carácter orgánico.

Pese a ello, no podemos conceptuar en su globalidad a la Ley 5/92 como orgánica, dado que su Disposición Final cuarta establece de

76 Lucas Murillo, P.: Informática y protección de datos, pp. 32 y 33. 
forma concreta qué disposiciones de la misma tienen rango de ley ordinaria, y cuáles, en todo caso, podrán ser modificadas sin observar las prescripciones que el artículo 81 de la C.E., y cuáles sí se acogen a tal contenido. De esta forma, podría decirse que la LORTAD queda subdividida en dos grandes apartados. Uno incluye los grandes principios $y$ las definiciones (la autodeterminación, el consentimiento de los afectados y las que configuran los derechos de las personas y sus límites, así como las que regulan el flujo transfronterizo de datos). Este primer grupo es partícipe del carácter orgánico. Por ello, su posibilidad de reforma está agravada, y las garantías se manifiestan con mayor vigor. En cambio, aquellas disposiciones que se refieren a los requisitos para la creación de ficheros, excepto la obligación de notificarla en el caso de los privados, y la de informar al afectado de la primera cesión de datos, la elaboración de códigos tipo, el estatuto y funciones de la Agencia de Protección de Datos, el régimen de infracciones y sanciones, entre otros, poseen el rango de ley ordinaria.

\subsection{3. Ámbito de la ley}

El ámbito de la norma, queda nítidamente definido en su artículo 2.1, cuando manifiesta que se extiende a todos aquellos datos de carácter personal que figuren en ficheros automatizados de los sectores público o privado. El mismo artículo amplía la virtualidad de la norma a los ficheros no automatizados, siempre que la información personal se encuentre sobre soportes físicos que sean susceptibles de tratamiento automatizado.

No obstante lo manifestado, la Disposición Adicional primera establece que a los ficheros automatizados de las Cortes Generales, el Defensor del Pueblo, el Tribunal de Cuentas, el Consejo General del Poder Judicial y el Tribunal Constitucional, no les son aplicables las normas de la LORTAD relativas a la supervisión de la Agencia de Protección de Datos, así como el régimen de infracciones y sanciones. Como es lógico deducir, esta excepción no exime del respeto de los contenidos y principios garantizados por la norma, a los citados órganos, únicamente da a entender que su especial situación institucional hace sobreentender determinadas garantías en su actuación.

Continúa el art. 2, en su apartado segundo, estableciendo que existen una serie de ficheros que en principio no están sometidos a ninguna regulación de datos personales, los cuales relacionamos: 
a) Los que siendo de titularidad pública, su objeto es la publicidad general.

b) Los que mantienen las personas físicas para su uso exclusivo.

c) Los que recogen información tecnológica y comercial que reproducen datos ya publicados.

d) Los ficheros de informática jurídica accesibles al público que reproduzcan disposiciones o resoluciones judiciales publicadas en periódicos o repertorios oficiales.

También son objeto de exclusión los ficheros de los partidos políticos, sindicatos, iglesias, confesiones y comunidades religiosas respecto de sus miembros. Pese a todo, esta exclusión no supone como afirma Lucas Murillo ${ }^{77}$ "... en modo alguno, la creación de una esfera de impunidad o exención para estos sujetos, ni deja sin garantía la observancia de las reglas sobre la cesión de datos o sobre los datos sensibles. Las salvedades que hace el art. 2.2.e), al apelar expresamente a los artículos 7 y 11 pueden amparar a mi juicio, la intervención de la Agencia de Protección de Datos respecto de esas cuestiones". Y de hecho existen ya expedientes y sanciones de la Agencia de Protección de Datos a algunos partidos politicos ${ }^{78}$, por la utilización indebida de la base de datos del censo electoral.

Para finalizar, el apartado tercero del artículo que venimos estudiando, excluye del ámbito de la LORTAD determinadas bases de datos o archivos, dado que tienen un contenido específico, por lo que habrán de ser regulados por normas especiales. De esta forma, los ficheros excluidos son:

a) Los contemplados en la legislación electoral, y que se rigen por el art. 41 de la L.O.R.E.G.

b) Los sometidos a la normativa sobre protección de materias clasificadas, que se rigen por ella (Ley se Secretos Oficiales).

c) Los del Registro Civil y los del Registro Central de Penados y Rebeldes.

77 Ibidem, p. 44.

78 Así ha ocurrido con el Partido Popular en la ciudad de Leganés (Madrid) en 1998. 
d) Los que tengan fines exclusivamente estadísticos, que quedan sometidos a la supervisión de la Agencia de Protección de Datos en lo relativo a la observancia de garantías.

e) Los que tengan por objeto el archivo de datos contenidos en los informes personales regulados en el art. 68 de la Ley $17 / 1989$, de 19 de julio, reguladora del régimen del personal militar profesional.

\subsubsection{Principios que establece la LORTAD}

Dos son, en esencia, los principios derivados de la norma sobre el tratamiento de datos: uno referido a los ficheros informatizados de carácter personal del sector público $y$ otro referido a los del sector privado.

A) Establece la LORTAD, refiriéndose a los ficheros de carácter personal del sector público, que todos los órganos e instituciones que intervengan en cualquier fase del tratamiento de datos personales se encuentran sometidos a la presente norma. Un grado superior de protección requieren los datos que cualquier ente u órgano administrativo realice sobre la finalidad, contenido y uso del tratamiento de datos.

Estos dos ámbitos o gradaciones de actuación por parte del poder público, respecto al tratamiento de datos, se han de adecuar a un compendio de principios establecidos en la norma que ahora estudiamos, y que a continuación resumimos:

- La norma habilita a la recopilación y procesamiento de datos personales, cuando sean adecuados, pertinentes y no excesivos en relación con el ámbito y las finalidades que pretende el fichero. Además habrán de ser los datos exactos $y$ actualizados. Se deberá, en todo caso, proceder a la cancelación o rectificación de aquellos datos que no obedezcan al fin para el que fueron recogidos.

- El titular de un banco de datos o fichero deberá adoptar las medidas necesarias y pertinentes para que no se produzca alteración, pérdida o accesos no autorizados a los datos. 
- Sobre los datos, los que los custodian y manejan, pesa la obligación del deber de secreto profesional, con independencia de la relación laboral que tengan, su categoria profesional, su nivel jerárquico o las funciones que cumplen dentro del proceso de recogida, tratamiento y almacenamiento de los datos.

- Otro de los principios capitales hace referencia al consentimiento del afectado. No obstante, existen excepciones a este principio, como son los datos recogidos de fuentes accesibles al público, cuando se recojan para el ejercicio o las funciones propias de las Administraciones Públicas en el ámbito de sus competencias, o por último, cuando se refieran a personas vinculas por una relación negocial, laboral, administrativa o contractual, y sean necesarias para el mantenimiento de tales relaciones.

- Por último, también recoge la LORTAD, como principio esencial, el de la información en la recogida de datos, por el cual debe informarse de forma expresa, precisa e inequívoca a aquellos a quienes se soliciten datos personales, de la existencia del fichero, así como la identidad y dirección del responsable del mismo. También harán constar, e informarán a la persona de quien tomen los datos, los derechos que poseen, los cuales son: el de impugnación de las valoraciones realizadas sobre datos informáticos; el de información al respecto de la base de datos, la finalidad e identidad de los responsables; el de acceso, para conocer los datos concretos que constan en el fichero, y por último, los derechos de cancelación y rectificación de los datos incompletos o inexactos.

La aplicación práctica de los principios que establece la LORTAD, deja en manos de los poderes públicos un ámbito de discrecionalidad muy significativo en la acción protectora del derecho a la intimidad informática. Ésta se manifiesta en seis contenidos de forma esencial79:

1. La cesión de datos personales puede realizarse de forma heterodoxa en dos supuestos: a) que una ley prevea la cesión de datos de un archivo a otro. Con ello se vulnera el princi-

79 Seguimos en este apartado el orden y algunos contenidos de las manifestaciones de Ruiz Miguel, de su obra citada, pp. 147 a 149. 
pio de la finalidad determinada. b) En segundo lugar, es posible la cesión de datos personales entre Administraciones Públicas si dicha cesión «hubiese sido prevista por las disposiciones de creación del fichero o por disposición posterior de igual o superior rango que regule su uso" ${ }^{80}$.

A ello, cabe añadir otro aspecto no contemplado en la ley. Lo constituye éste, si el consentimiento ha de ser realizado de forma expresa por el afectado, o es suficiente con la no oposición del mismo. Parece más adecuado a la plena garantía del derecho, inclinarse por la primera opción.

2. La LORTAD excluye el derecho de información del afectado en la recogida de los datos cuando esa información «impida o dificulte gravemente el cumplimiento de las funciones de control y verificación de las Administraciones Públicas o cuando afecte a la Defensa Nacional, a la seguridad pública o la persecución de infracciones penales o administrativas»81. Este contenido no lo es del Convenio de 1981, con lo cual el Estado firmante de aquel Convenio está rebajando el umbral de protección, lo cual, desde una perspectiva objetiva y jurídica, no parece demasiado ajustado a la Constitución.

3. No parece tampoco muy acorde a la constitucionalidad, las excepciones que se formulan a los derechos de acceso, rectificación y cancelación, los cuales han de ser puestos de manifiesto por el órgano administrativo en resolución motivada. La fundamentación, en todo caso ha de ser de «interés público" o «intereses de terceros", y ello es una considerable indeterminación jurídica.

4. Los mismos derechos citados en el apartado anterior, acceso, rectificación y cancelación, se desvanecen ante la Hacienda Pública. Los responsables de estos ficheros, pueden denegar el ejercicio de tales derechos "cuando el mismo obstaculice las actuaciones administrativas tendentes a asegurar el cumplimiento de las obligaciones tributarias, y en todo caso, cuando el afectado esté siendo objeto de actuaciones inspectoras ${ }^{82}$. De esta forma se la otorga a la $\mathrm{Ha}-$ 
cienda Pública la facultad de decidir sobre el contenido esencial de un derecho fundamental desde una posición de absoluta supremacia.

5. Según el texto actual de la LORTAD una serie de los llamados datos sensibles (origen racial, salud, vida sexual) pueden ser recabados, tratados y cedidos, sin consentimiento del afectado "cuando por razones de interés general así lo disponga una ley» ${ }^{83}$. Al no estar contenido el art. 7.3 en la exclusión que realiza la Disposición Final 3. ${ }^{a}$, parece lógico entender que el carácter de la ley gue limite su contenido, deberá ser en todo caso orgánica.

6. Por último, hemos de afirmar, que los ficheros de los cuerpos y fuerzas de seguridad, tienen un régimen jurídico especialmente lesivo de la intimidad informática. En primer lugar, se vulnera el principio de consentimiento de los afectados $^{84}$. Además se establece que la recogida y tratamiento de los datos sensibles upodrán realizarse exclusivamente en los supuestos en que sea absolutamente necesario para los fines de una investigación concreta» ${ }^{85}$. También, los responsables de los ficheros de las fuerzas policiales "podrán denegar el acceso, la rectificación o la cancelación en función de los peligros que pudieran derivarse para la defensa del Estado o la seguridad pública, la protección de los derechos y libertades de terceros o las necesidades de las investigaciones que se estén realizando" ${ }^{86}$.

B) Como habíamos apuntado, aun siendo los aspectos más significativos de la LORTAD los que hacen relación a los órganos públicos, hay que tener en cuenta que también es de aplicación la ley a los datos personales que figuren en ficheros automatizados del sector privado (art. 2.1. $)$, a excepción de los ya conocidos, como son los que mantengan partidos políticos, sindicatos, iglesias, confesiones o comunidades religiosas, en tanto en cuanto, los datos se refieran a sus asociados, miembros o ex-miembros. Excluido lo anterior, puede entenderse, que en las relaciones entre particulares rigen los mismos 
principios y derechos que rigen entre los poderes públicos y los titulares del derecho a la intimidad informática, de lo que se deduce, que en estas relaciones el plano es de igualdad y equilibrio, y lo es de forma más significativa, siendo por tanto la protección de la intimidad informática, verdaderamente efectiva. Pese a ello, pueden surgir algunos problemas con la interpretación de la cesión de ficheros entre particulares. Así, el responsable de un fichero privado no tiene el deber de informar, al efecto de la primera cesión de datos que haya efectuado "cuando el establecimiento del fichero automatizado responda a la libre y legitima aceptación de una relación jurídica cuyo desarrollo, cumplimiento y control implique necesariamente la conexión de dicho fichero con ficheros de terceros. En este caso solo será legitima en cuanto se limite a la finalidad que la justifica ${ }^{87}$. Como entiende Ruiz Miguel ${ }^{88}$, "en los de empleadores o de compañías de seguros es fácil alegar que el desarrollo, cumplimiento y control de la relación jurídica implica la conexión de sus ficheros con los de terceros, en cuyo caso puede procederse a la cesión de datos no sensibles sin consentimiento".

No procede ahora entrar en un estudio pormenorizado del articulado de la LORTAD, pero si entendemos que procede hacer una valoración, aunque sea somera de su contenido, dada su capital importancia al respecto de la intimidad. Se puede afirmar en un principio que el planteamiento genérico de la ley sigue la dinámica planteada por la regulación concerniente a todo aquello que es novedoso, es decir, la desconfianza.

Más útil, entiendo, hubiera sido hacer una configuración legislativa basada en la idea de que las modernas técnicas de comunicación tienen un aspecto más positivo que negativo, sin olvidar por ello que éstas pueden ser utilizadas con fines distintos, y por lo tanto lesivos para los derechos constitucionalmente reconocidos, pero a su vez, no cabe duda de que la virtualidad de esta ley, se refuerza con la creación de instituciones como el Registro General de Protección de Datos y la Agencia de Protección de Datos, los cuales garantizan y facilitan el ejercicio de los derechos de información y acceso de las ciudadanos a los ficheros de titularidad tanto pública como privada. Por último cabe afirmar la falta de concreción de algunos artículos que pueden producir una interpretación sesgada del querer constitucional, pese a ser éste 
un riesgo de toda norma, puede adquirir una mayor lesividad en aspectos relacionados con el derecho a la intimidad.

Las garantías de la intimidad tienen hoy un contenido positivo en referencia a los datos de la propia persona. Ello se concreta, vista la legislación, en que los ciudadanos puedan conocer la existencia y los fines de los ficheros en los que pueden estar insertos datos a ellos referentes. Por tanto y como afirma la sentencia del Tribunal Constitucional del 20 de julio de 1993 «...dichas facultades de información forman parte del contenido del derecho a la intimidad, que vincula directamente a todos los poderes públicos...».

Pese a una valoración global positiva del contenido de la Ley Orgánica 5/1992, de 29 de octubre, sobre todo por la necesidad que viene a paliar, y por los mecanismos de protección que establece, pueden reseñarse contenidos que quedan ambiguos, o con un grado de discrecionalidad en su uso y aplicación muy significativo, y sobre manera, en lo que hace referencia a los denominados datos sensibles. Es verdad, que el Estado en orden al bien público está en la necesidad de conocer aspectos concretos de la vida del ciudadano (salud, seguridad del Estado, etc.), pero ello ha de realizarse con las medidas necesarias de cautela para mantener el equilibrio entre los derechos. Al igual que hemos criticado al constituyente por dejar escapar la oportunidad de concretar en mayor rango legal lo concerniente al "habeas data", cabe reprochar al legislador la improcedencia de no determinar y concretar éstos aspectos conflictivos que van a quedar en manos de la Administración a través del desarrollo reglamentario, que indefectiblemente será quien en último lugar aporte luz sobre las partes oscuras tanto de la regulación constitucional como del desarrollo legislativo. No obstante, cabe tener la confianza en que le es más fácil al Tribunal Constitucional discernir los límites de los derechos al honor, la intimidad y propia imagen después de 1992.

\subsection{Real Decreto 428/1993, de 26 de marzo}

EI Título VI de la LORTAD configura la Agencia de Protección de Datos como un Ente de Derecho Público, con personalidad jurídica propia y plena capacidad pública y privada, y que actúa con plena independencia en el ejercicio de sus funciones. Establecen los arts. 34 y siguientes del texto que venimos citando, su naturaleza y régimen jurídico (art. 34) y sus funciones (art. 36). Por su parte, la Disposición Fi- 
nal primera de la LORTAD habilita al Gobierno para dictar las disposiciones necesarias para la aplicación, desarrollo y regulación de la estructura orgánica de la Agencia de Protección de Datos. En virtud de esta delegación legislativa surge el Real Decreto 428/1993, por el que se aprueba el Estatuto de la Agencia de Protección de Datos.

No cabe duda de que los ordenamientos jurídicos europeos han entendido como sumamente funcional y efectiva la institucionalización de un órgano independiente que controle toda la actividad relacionada con el tratamiento de datos. Esta idea, que parte del ordenamiento jurídico estadounidiense, se instaura en el español con plena garantía de efectividad. Para ello se dota a la Agencia de potestad normativa (informa los proyectos de disposiciones que afecten al tratamiento de datos, tiene potestad para realizar Instrucciones y Recomendaciones, para adecuar los tratamientos automatizados a los principios de la LORTAD). También se establecen especiales garantías para el nombramiento y la permanencia de los cargos directivos, los cuales tienen su origen en un órgano colegial, como es el Consejo Consultivo. Otro elemento de garantía de independencia lo constituye el aspecto financiero, si bien aquí ha de manifestarse que la Agencia carece de fuentes de financiación propias, dependiendo de los Presupuestos Generales del Estado; pese a ello, la Agencia elabora un anteproyecto de presupuesto anual. Por último, podemos entender como elemento de garantía de independencia, la capacidad de relación que tiene la Agencia con otros órganos de la Administración. Aunque las relaciones Agencia-Gobierno, han de realizarse a través del Ministerio de Justicia, ello no es óbice, para que la Agencia tenga acceso directo a cualquier órgano, de cualquier Administración Pública. La Agencia se relaciona también con las Cortes Generales, mediante la presentación de una memoria anual. En el ámbito internacional, también está relacionada y en concreto con toda la actividad de flujo de datos, con los órganos creados en otros Estados con el mismo fin.

En definitiva, puede manifestarse que el legislador español de 1992 (LORTAD) y de 1993 (Real Decreto 428/1993) se anticipa al contenido del art. 28 de la Directiva 95/46/CE, que obliga al establecimiento de una autoridad de control, encargada de vigilar la aplicación de las normas relativas la tratamiento de datos de carácter personal, si bien esta última norma tiene algunas repercusiones sobre todo en el funcionamiento de la Agencia, que serán analizadas con posterioridad al estudio que ahora abordamos, y que hace relación a las funciones de la Agencia de Protección de Datos. 
Antes de abordar de forma concreta las funciones, hemos de advertir que éstas no se encuentran solo en el Real Decreto 428/1993, sino que también las regula el art. 36 de LORTAD, y tiene implicaciones el Real Decreto 1.332/1994, de 20 de junio. Del análisis de los tres textos normativos se obtiene la siguiente asignación de funciones a la Agencia de Protección de Datos:

1. La Agencia realiza una función esencialmente informativa, dando publicidad y acceso a los ficheros y a los tratamientos a través del Registro General de Protección de Datos. Para ello realizará campañas de difusión y publicará periódicamente relación de los ficheros. También debe realizar una memoria de su actividad que enviará al Ministerio de Justicia y a las Cortes Generales.

2. Realiza también la Agencia una función consultiva, que se concreta en realizar informes de los proyectos de disposiciones generales que desarrollen la LORTAD. De forma genérica, asiste al Gobierno, asesorándole de las implicaciones en lo relativo a la protección de datos, de las futuras normas.

3. Es competencia de la Agencia, velar por el cumplimiento de la legislación relativa a la protección de datos, y en especial, a la salvaguardia y tutela de los derechos de información y defensa de los afectados. En base a ello, se canalizan a través de la Agencia, las peticiones y reclamaciones de los afectados (art. 4.2 del R.D. 428/1993).

4. $\quad$ No está desprovista la Agencia, de potestad normativa concreta, en el ámbito de sus competencias. De esta forma, está habilitada para dictar Instrucciones y Recomendaciones, siempre que sean necesarias para adecuar los tratamientos automatizados a los principios de la LORTAD, o para fijar las condiciones de los ficheros de los servicios estadísticos públicos. Esta función se muestra como capital, si tenemos en cuenta que las Instrucciones establecen la interpretación del contenido de la LORTAD.

5. Para cumplir adecuadamente sus funciones, es necesario otorgar a la Agencia, como Administración independiente que es, la posibilidad de recabar de los responsables de los ficheros, cuanta ayuda o información considere necesaria. También tiene la potestad, de supervisar el funcionamiento 
de los ficheros así como el tratamiento que se realiza de los datos. Más imperativa, se muestra la norma, respecto de los ficheros contemplados en la LORTAD, sobre ellos, la Agencia tiene la potestad de inspección. Ello compensa en cierta medida la deficiencia o posible vulneración del derecho a la intimidad por parte de los poderes públicos.

6. Otra de las funciones significativas que la Agencia desarroIla a través de la figura de su Director, lo constituye la función coordinadora y preventiva. Esta no viene recogida en el art. 36 de la LORTAD, y si en los arts. 40 y 41 del Real Decreto $428 / 1993$.

7. Realiza la Agencia, en virtud del art. 42 de la LORTAD, una función represiva, a través de su potestad sancionadora. Ello se ha visto favorecido, por el contenido del art. $197.2 \mathrm{del}$ nuevo Código Penal, que tipifica las conductas consistentes en apoderarse, utilizar o modificar, en perjuicio de terceros, datos reservados de carácter personal o familiar o de otro tipo, que se hallen registrados en ficheros o soportes informáticos, electrónicos o telemáticos, o cualquier otro tipo de archivo o registro público o privado. De la misma forma, castiga a quien sin autorización acceda a los ficheros, los altere o utilice en perjuicio del titular o de un tercero.

8. Por último, el art. 36 de la LORTAD, en el apartado 1, le otorga a la Agencia la función de representante español ante el Grupo de Protección de las Personas (art. 29 de la Directiva). Además de ello, tiene encomendada la Agencia la función de cooperación internacional en el ámbito específico de su actividad.

Analizadas las funciones que el ordenamiento jurídico español atribuye a la Agencia, nos cabe preguntarnos si los contenidos de esta entran en contradicción con la Directiva 95/46, o por el contrario, si la configuración de la Autoridad de Control que la citada Directiva realiza, es plenamente acorde con la actual configuración de la Agencia como Administración independiente. Del estudio que hemos realizado del ordenamiento jurídico español, no se derivan diferencias substanciales en cuanto a configuraciones y cometidos, del órgano que configura la Directiva 95/46. Ambas normativas persiguen la constitución de un organismo con una posición institucional fuerte, con capacidad funcional efectiva, y todo ello con el objetivo primordial de la salvaguarda de la 
libertad, los derechos fundamentales, y en esencia de protección de la intimidad ante la informática y los modernos medios de comunicación.

Pese a ello, se advierte que la intencionada no distinción por parte de la Directiva entre ficheros de carácter público y privado, se constituyen en una mayor virtualidad y funcionalidad de la Autoridad de control. Ello se manifiesta en esencia, en que la Directiva posibilita un acceso indirecto de los afectados a los datos, a través de la Autoridad de Control, supuesto que no se contempla en el ordenamiento jurídico español, pese a que en los debates parlamentarios al respecto de la LORTAD, se barajó tal posibilidad. Cabe apreciar también alguna diferencia, en la potestad sancionadora de la Autoridad de Control, con respecto a la Agencia, en lo que atañe a las infracciones cometidas por órganos de la Administración o Funcionarios públicos, ya que aqui las potestades de la Agencia se difuminan de forma considerable.

\subsection{Directiva 95/46/CE del Parlamento Europeo y del Consejo de 24 de octubre de 1995}

Con fecha 24 de octubre de 1995 se aprueba la Directiva 95/46/CE, relativa a la protección de personas físicas en lo referido al tratamiento de datos personales y a su libre circulación. Establece la Directiva, la necesidad de cumplir en un plazo de tres años (art. 32), la acomodación de las normativas nacionales al contenido de la misma.

Parece claro que la Directiva viene a ampliar y concretar el ámbito que al respecto de la protección de datos ya había delimitado el Convenio de 1981. La disparidad legislativa de los Estados miembros, asi como el desfase o la generalidad del Convenio, hacían necesaria una normativa más concreta y detallada, un substrato común en cuanto a la protección de datos y la preservación del derecho a la intimidad con un ámbito europeo o supranacional.

De esta forma, en 1995, el Parlamento Europeo y el Consejo de la Unión Europea pretenden garantizar por parte de los Estados miembros, "la protección de la libertades y los derechos fundamentales de las personas físicas, $y$, en particular, el derecho a la intimidad, en lo relacionado con el tratamiento de datos personales» ${ }^{89}$. Nótese que la Di- 
rectiva establece como eje central de su contenido, el derecho a la intimidad. Apuntamos este dato en relación con lo manifestado en el apartado II de este trabajo, y de forma concreta a las distinciones conceptuales.

Al igual que la LORTAD en su art. 3, la Directiva dedica su artículo 2 a las definiciones de términos clave en la protección de datos, no pudiendo deducirse variación alguna en cuanto a los contenidos esenciales, y a la interpretación de los términos. En todo caso, se observa una mayor definición, o amplitud de los mismos, en la Directiva.

En lo referente al ámbito de aplicación, las semejanzas con la LORTAD también son muy significativas. El art. 3 de la Directiva, establece con carácter general, que sus disposiciones se aplicarán al tratamiento total o parcialmente automatizado de datos personales, así como al tratamiento no automatizado de datos personales contenidos o destinados a ser incluidos en un fichero. De esta forma, la Directiva regula los datos personales, tanto automatizados como manuales. Así pues, la disparidad con la LORTAD es menos significativa de lo que en un primer momento pudiera parecer. Si bien es cierto que la LORTAD únicamente se refiere a los datos personales automatizados, también lo es, que existe la previsión (Disposición Final segunda), de que el Gobierno, previo informe del Director de la Agencia de Protección de Datos, pueda extender la protección de la Ley Orgánica, a los ficheros que contengan datos almacenados de forma convencional, y que no hayan sido sometidos aún a tratamiento automatizado. La Directiva, en su art. 32.2, establece un plazo de 12 años, con lo cual, el legislador, o el ejecutivo en España, tiene de plazo hasta el año 2007, para someter a la LORTAD los denominados ficheros manuales.

Vista esta primera aproximación al contenido del ámbito de la $\mathrm{Di}$ rectiva, en relación a lo establecido en la LORTAD, no deja de plantearnos algunas dudas. La Directiva, además de excluir el tratamiento efectuado por una persona física en el ejercicio de actividades exclusivamente personales o domésticas, supuesto que coincide con los del art. 2.2.b) de la LORTAD, se refiere a las disposiciones establecidas en los Títulos V y VI del Tratado de la Unión Europea, y en cualquier caso cuando el tratamiento tenga por objeto la seguridad pública, la defensa, la seguridad del Estado y las actividades del Estado en materia penal. Parece lógico deducir, que los contenidos del art. 3.2 apartado primero de la Directiva y art. 2 de la LORTAD originarán considerables problemas de interpretación y aplicación. También parece lógico pensar que la solución habrá de venir por la vía de la interpretación jurisprudencial, tanto nacional como comunitaria. 
Parece más clara la eliminación de la exclusión del ámbito de la aplicación de la LORTAD de los ficheros automatizados de titularidad pública cuyo objeto, legalmente establecido, sea el almacenamiento de datos para su publicidad con carácter general y a los ficheros de información tecnológica y comercial que reproduzcan datos ya publicados en boletines, diarios o repertorios oficiales, dado que el art. 3 de la $\mathrm{Di}$ rectiva no excluye ese tipo de ficheros.

Nos queda por último, analizar la situación de los ficheros de partidos políticos, sindicatos e iglesias, al respecto de sus asociados, miembros o ex-mienbros. Aquí recogemos la opinión de Martín-CasaIlo, cuando manifiesta, que "desde mi punto de vista, nunca he llegado a comprender la razón de la exclusión de dichos ficheros del ámbito de aplicación de la Ley Orgánica, salvo el supuesto de la cesión, máxime si tenemos en cuenta que en ellos siempre existen datos reveladores de ideología, religión o creencias, como tácitamente admite el texto legal en su referencia al art. 7 de la Ley Orgánica»"90.

Con todo, el posible choque entre la regulación de la Directiva y la LORTAD, no se agota con los contenidos del art. 2 de ésta última, ya que cabe la posibilidad de regulación de otros ficheros por normas específicas.

Como en la propia LORTAD, también existen excepciones o exclusiones de su ámbito de aplicación en la Directiva, las cuales resumimos:

- No será de aplicación la Directiva, a los tratamientos efectuados como consecuencia de actividades exclusivamente personales o domésticas, como la correspondencia y el manejo de un repertorio de direcciones (Considerando 12).

- También quedan excluidos de este ámbito, el contenido de los Títulos V y VI del Tratado de la Unión Europea relativos a la seguridad pública, defensa, seguridad del Estado y actividades del Estado en el ámbito penal (Considerando 13).

- Quedan excepcionados también el tratamiento de datos necesario para la salvaguardia del bienestar económico, cuan-

90 Martín-Casallo López, J. J.: «Implicaciones de la Directiva sobre protección de datos en la normativa española». En la obra coordinada por Davara RoDRíguez, $X$ años de encuentros sobre Informática y Derecho, Aranzadi, Madrid, 1997, p. 83. 
do dicho tratamiento está relacionado con la seguridad del Estado (Considerando 13).

- Tampoco es objeto de la presente Directiva lo relativo al tratamiento de datos que concierna a personas jurídicas (Considerando 24).

Dos aspectos nos quedan por analizar en la Directiva para dejar visto su ámbito de aplicación. Uno primero hace referencia al Considerando 24 , en virtud del cual se entienden bajo la aplicación de la Directiva, todos los datos a los que tradicionalmente se han venido considerando como datos personales. Aquí habría que entender que se trata de una remisión al Convenio de 1981, y en nuestro caso, a la cobertura de protección que otorga la LORTAD.

Un último aspecto relacionado con el ámbito de protección, lo encontramos en una apertura de las lindes del derecho a la intimidad. De esta forma, el Considerando 14 de la Directiva establece que "habida cuenta de la importancia que, en el marco de la sociedad de la información, reviste el actual desarrollo de las técnicas para captar, transmitir, manejar, registrar, conservar o comunicar los datos relativos a las personas físicas constituidos por sonido e imagen, la presente Directiva habrá de aplicarse a los tratamientos que afecten a dichos datos". Este aspecto no estaba contemplado por la LORTAD, aunque bien es verdad, que esta laguna, en el ordenamiento jurídico español había sido subsanada por el Real Decreto 1.332/1994, que desarrolla determinados aspectos de la Ley Orgánica 5/1992. No podemos obviar, en todo caso, su distinto rango normativo.

Por lo que hace referencia a los principios de la Directiva, hemos de distinguir, porque asi lo hacen los artículos 6 y 7 , entre principios relativos a la calidad de los datos y los relativos a la legitimación del tratamiento de datos. Al respecto de los primeros, observamos que el art. 6 de la Directiva recoge en esencia y casi con literalidad el contenido del art. 5 del Convenio de 1981. Establece la Directiva cinco principios esenciales con respecto a la calidad de los datos:

a) Los datos han de ser tratados de manera leal y lícita.

b) Los fines a que obedece la recogida de datos habrán de ser determinados, explícitos y legítimos. Estas limitaciones afectan también a su tratamiento posterior. Se exceptúa del tratamiento posterior, los datos con fines históricos, estadísticos o científicos, siempre y cuando los Estados miembros establezcan las garantías oportunas. 
c) Los datos han de ser adecuados, pertinentes y no excesivos con relación a los fines para los que se recaben y para los que se traten posteriormente.

d) También habrán de ser los datos exactos $y$, cuando sea necesario, actualizados. Los datos inexactos o incompletos serán suprimidos o rectificados.

e) Por último, se establece como principio, el que los datos han de ser conservados en una forma que permita la identificación de los interesados durante un período no superior al necesario para los fines para los que fueron recogidos o para los que se traten posteriormente.

En lo que hace referencia a los principios relativos a la legitimación del tratamiento de datos, estos se recogen en el art. 7 de la Directiva. El cual es muy taxativo en su expresión al establecer que «los Estados miembros dispondrán que el tratamiento de datos personales sólo podrá efectuarse si...", para establecer a continuación los seis principios básicos relativos al tratamiento de datos, los cuales resumimos:

a) El interesado ha de prestar su consentimiento de forma inequívoca.

b) Únicamente cabe el tratamiento de datos, si es necesario para la ejecución de un contrato en el que el interesado sea parte o para la aplicación de medidas precontractuales adoptadas a petición del interesado.

c) También puede efectuarse el tratamiento, si es necesario para el cumplimiento de una obligación jurídica a la que esté sujeto el responsable del tratamiento.

d) Si es necesario, para proteger el interés vital del interesado.

e) Para el cumplimiento de una misión de interés público o inherente al ejercicio del poder público conferido al responsable del tratamiento, o de un tercero a quien se comuniquen los datos.

f) Por último, es necesario para la satisfacción del interés legitimo perseguido por el responsable del tratamiento o por el tercero o terceros a los que se comuniquen los datos, siempre que no prevalezca el interés o los derechos y libertades fundamentales del interesado, o que requieran protección con arreglo al apartado primero del artículo 1 de la presente Directiva. 
Además de los principios que hemos recogido, y que se encuentran insertos en los artículos citados. La Directiva está prologada por un total de 72 considerandos, en los cuales, a su vez, también se recogen y desarrollan principios de aplicación o interpretación del articulado. Destacamos los siguientes, agrupados en conceptos:

1. Tratamiento lícito: Se considera que un tratamiento de datos personales es lícito cuando se efectúa con el fin de proteger un interés esencial para la vida (Considerando 31).

2. Consentimiento: Los datos que por su naturaleza puedan atentar contra las libertades fundamentales o intimidad, únicamente pueden ser tratados si existe el consentimiento explícito del interesado (Considerando 33). En los datos del interesado no recogidos por quien realiza el tratamiento, sino por otro sujeto, así como cuando se comunican datos a un tercero y su comunicación no estaba prevista en el momento de la recogida, en ambos casos debe informarse al interesado en el momento del registro de los datos, o a más tardar, al comunicarse los datos por primera vez a un tercero (Considerando 39). Pese a lo anterior, se exceptúan los supuestos en que el interesado esté informado; si el registro o la comunicación están expresamente previstos por la ley; o si resulta imposible informarle o implica esfuerzos desproporcionados (Considerando 40).

3. Finalidad: Se entiende por tratamiento leal, aquel en el que el interesado conozca la existencia del tratamiento y que se le informe en la recogida del dato de manera precisa y completa de cual será su tratamiento y utilización (Considerando 38$)$.

4. Derecho de acceso: El Considerando 41 recoge el derecho de acceso como método de comprobación de la exactitud y licitud del tratamiento, así como la posibilidad de conocer el sistema lógico que subyace al tratamiento automatizado. EI Considerando 42 admite que, en beneficio del interesado, pueden limitarse los derechos de acceso e información.

5. Seguridad: Se obliga a la garantía en la seguridad de los datos (Considerando 46) y que el individuo tiene derecho a oponerse a que los datos que le conciernen, sean objeto de un tratamiento en virtud de motivos fundados y legítimos relativos a su situación concreta (Considerando 45). 
Con independencia del punto que nos queda por abordar (transferencia de datos personales a países terceros), los demás contenidos de la Directiva, parecen ir más encaminados hacia constituirse como un umbral mínimo en cuanto a la protección de datos de los Estados miembros. Y ello es así porque, como puede observarse con un ligero repaso al contenido de la Directiva, la mayoría, o la inmensa mayoría de las prescripciones de la misma, son contenido de la LORTAD, o del resto de legislación española relativa al tratamiento de datos.

No ocurre lo mismo, como hemos manifestado, con lo relativo a la transferencia de datos personales a países terceros. Esto en buena lógica jurídica, ha de ser regulado por norma de ámbito supranacional, debido a que de lo contrario, se entraría en un sistema anárquico de cesión de datos internacionales. El artículo 25 de la Directiva viene a solventar esta problemática, estableciendo para ello una serie de principios en la cesión de datos a terceros paises. Estos, podemos resumirlos en base a lo siguiente:

La cesión ha de ser acorde con el derecho nacional y únicamente podrá realizarse en el caso, de que el país que recibe los datos, tenga un nivel de garantía de los mismos adecuado. Se supone que la adecuación se mide en base a lo pareja que esté la protección de datos con la regulación europea. En particular, sigue afirmando el apartado segundo del art. 25, se tomará en consideración la naturaleza de los datos, la finalidad y la duración del tratamiento o tratamientos previstos, el país de origen y el país de destino final, el derecho vigente en el pais al que van dirigidos los datos y sus medidas de seguridad.

Como en toda norma genérica, su limitación se realiza fundamentalmente a base de excepciones, y la Directiva que estudiamos, no se aleja para nada de esta técnica jurídica. Por ello, el art. 26, contiene las excepciones al contenido genérico del art. 25. Podemos resumir aquél de la forma siguiente:

- Se puede dar la cesión, aún no garantizando el tercer Estado, un nivel de protección adecuado, si ofrece garantía suficiente al respecto de la protección de la vida privada, los derechos y libertades fundamentales de las personas.

- También se excepciona la garantía del tercer Estado cuando:

a) El interesado haya dado su consentimiento inequivocamente a la transferencia prevista. 
b) Cuando la transferencia sea necesaria en virtud de un contrato entre el interesado $y$ el responsable del tratamiento, o para la ejecución de medidas precontractuales tomadas a petición del interesado.

c) También se dará la excepción, cuando la transferencia sea necesaria para la celebración o ejecución de un contrato celebrado o por celebrar en interés del interesado, entre el responsable del tratamiento y un tercero.

d) Cuando la transferencia sea necesaria o legalmente exigida para la salvaguardia de un interés público importante, o para el reconocimiento o ejercicio de un derecho.

e) Cuando se trate de la salvaguardia del interés vital del interesado.

f) Por último, se excepciona la prohibición, cuando la transferencia tenga lugar desde un registro público que, en virtud de disposiciones legales o reglamentarias, esté concebido para facilitar información al público y esté abierto para consulta del público en general, o por cualquier persona que pueda demostrar un interés legítimo.

\subsection{Directiva 97/66/CE del Parlamento Europeo y del Consejo} de 15 de diciembre de 1997

Antes de entrar de forma escueta en su contenido, conviene recordar, que su transposición es obligatoria antes del 24 de octubre de 1998, y los Estados miembros habrán de poner en vigor las disposiciones legales, reglamentarias o administrativas necesarias, para garantizar la confidencialidad de las comunicaciones a través de redes públicas, antes del día 24 de octubre del año 2000.

El objeto esencial de esta Directiva es, como establece el art. 1, armonizar las disposiciones relativas a protección de datos, de los distintos Estados, con objeto de garantizar "un nivel equivalente de protección de las libertades y de los derechos fundamentales y, en particular, del derecho a la intimidad, en lo que hace referencia al tratamiento de datos personales en el sector de las comunicaciones".

A continuación, y como es útil costumbre jurídica en las regulaciones sobre nuevas tecnologías, se establecen las pertinentes definiciones jurídicas. 
Interesa destacar que el propósito de la Directiva radica en establecer las obligaciones y derechos tanto de abonados como de proveedores, en el ámbito de las telecomunicaciones. Además de ello, se regulan tambien obligaciones y derechos al respecto de datos de carácter personal.

De esta forma, el proveedor de un servicio público de telecomunicación esta obligado a preservar la seguridad de sus servicios, a garantizar la confidencialidad de las comunicaciones que son objeto del servicio. También se limitan, de forma tasada, los datos que el proveedor puede almacenar al respecto del usuario, rigiendo en lo demás el contenido de la Directiva 95/46 CE.

Por último, es de destacar que los datos personales recogidos en las guías impresas o electrónicas accesibles al público o que puedan obtenerse a través de servicios de información, deberán limitar su contenido a lo estrictamente necesario para identificar al abonado concreto, a menos que el abonado haya dado su consentimiento inequívoco, para que se publiquen otros datos personales. El abonado, tiene derecho a que se le excluya gratuitamente de la citada guía. 